\title{
Filamentous Bacteriophage: Biology, Phage Display and Nanotechnology Applications
}

\author{
Jasna Rakonjac ${ }^{1 *}$, Nicholas J. Bennett ${ }^{1 \S}$, Julian \\ Spagnuolo $^{1}$, Dragana Gagic ${ }^{1 \dagger}$ and Marjorie Russel ${ }^{2}$ \\ ${ }^{1}$ Institute of Molecular BioSciences, Massey University, \\ Palmerston North, New Zealand \\ ${ }^{2}$ The Rockefeller University, New York, NY, USA \\ ${ }^{\dagger}$ Current address: AgResearch Grasslands, Palmerston \\ North, New Zealand \\ \$Current address: Department of Microbiology and \\ Immunology, McGill University, Montreal, Quebec, Canada
}

\begin{abstract}
Filamentous bacteriophage, long and thin filaments that are secreted from the host cells without killing them, have been an antithesis to the standard view of head-and-tail bacterial killing machines. Episomally replicating filamentous phage Ff of Escherichia coli provide the majority of information about the principles and mechanisms of filamentous phage infection, episomal replication and assembly. Chromosomally-integrated "temperate" filamentous phage have complex replication and integration, which are currently under active investigation. The latter are directly or indirectly implicated in diseases caused by bacterial pathogens Vibrio cholerae, Pseudomonas aeruginosa and Neisseria meningitidis. In the first half of the review, both the $\mathrm{Ff}$ and temperate phage are described and compared. A large section of the review is devoted to an overview of phage display technology and its applications in nanotechnology.
\end{abstract}

\section{Introduction}

The archetypal bacteriophage has a head and a tail; it injects its linear double-stranded DNA, blocks the host's vital processes, replicates and assembles new virions in the cytoplasm, ultimately lysing the host cell in order to release the progeny. Some dramatically different bacteriophage, however, both in the terms of morphology and lifestyle, exist in Nature. One such group are phage of the genus Inovirus, commonly called filamentous bacteriophage - long, thin filaments containing a circular single-stranded DNA genome. Even more radically different than their morphology is their relationship to the host - filamentous phage reproduce without killing the host, and some even take part in the host's "social" life - i.e. the dynamics of biofilms, as has been recently reported for Pseudomonas aeruginosa phage Pf4 (Rice et al., 2009). Filamentous bacteriophage are widespread among Gram-negative bacteria, infecting a wide range of genera including Escherichia, Salmonella, Pseudomonas, Xanthomonas, Vibrio, Thermus and Neisseria (Table 1; Russel and Model, 2006). There are only two published reports of filamentous phage that infect Gram-positive organisms (Chopin et al., 2002; Kim and Blaschek, 1991). In total around 60 different filamentous phage have been described to date (International Committee on Taxonomy of Viruses., 2005), but their number is likely

\section{*Corresponding author: Email: j.rakonjac@massey.ac.nz}

much larger, given that many replicate too poorly to affect the host and hence their detection by observing plaques on host cell lawns is not possible (Table 1).

The filamentous phage of Escherichia coli are the most productive phage in Nature, giving rise to titers of up to $10^{13}$ per $\mathrm{mL}$ of culture. This productivity is coupled to slowing down the host's growth and leads to formation of turbid plaques on bacterial lawns. Among E. coli filamentous phage, the beststudied and most-exploited group are the $\mathrm{F}$ pilus-specific phage or Ff, known as $\mathrm{f} 1, \mathrm{M} 13$ and fd (Hoffman-Berling et al., 1963; Hofschneider, 1963; Loeb, 1960), 98.5\% identical in their DNA sequence (ICTVdB, 2008; International Committee on Taxonomy of Viruses., 2005). These three phage have interchangeably been featured, not only as a model system in understanding membrane transactions, but also in combinatorial technologies, whose most influential product are therapeutic recombinant antibodies (Bradbury and Marks, 2004) and the most unexpected - a lithiumpowered nano-battery (Lee et al., 2009). Members of a large group of temperate filamentous bacteriophage are directly or indirectly implicated in pathogenesis of Vibrio cholerae, Neisseria meningitidis and Pseudomonas aeruginosa (Bille et al., 2008; Waldor and Mekalanos, 1996; Webb et al., 2004).

\section{The virion}

The overwhelming majority of what we know about the filamentous phage virion structure comes from $\mathrm{Ff}$ phage of $E$. coli and Pf1 of $P$. aeruginosa. Unless otherwise stated, this review will be referring to $\mathrm{Ff}$ phage ( $\mathrm{f} 1, \mathrm{fd}$ and $\mathrm{M} 13$ ). The simplicity of the virion filament is matched by the small number of proteins that form it (Figure 1). The filament tube is formed by thousands of helically arranged copies of pVIII, a small protein of only 50 amino acids. The ends of the filament are built by two different pairs of proteins $-p V I-p I X$ and pllI-pVI.

\section{Major coat protein pVIII}

The major coat protein $\mathrm{pVIII}$ is an integral inner membrane protein prior to assembly into the virion. PVIII of $\mathrm{Ff}$ and $P$. aeruginosa Pf3 have been used extensively to investigate the mechanism of protein insertion into phospholipid bilayers; it was in fact the vehicle for discovery and characterization of bacterial protein YidC that mediates insertion of small hydrophobic proteins into the inner membrane in a Sec translocon-independent manner (Rohrer and Kuhn, 1990; Samuelson et al., 2000; Serek et al., 2004). Interestingly, $\mathrm{pVIII}$ of $\mathrm{Ff}$ contains a signal sequence whereas Pf3 pVIII does not; yet they use the same mechanism for insertion into the inner membrane. A C-terminal hydrophobic transmembrane helix anchors $\mathrm{pVIII}$ in the inner membrane prior to assembly (Papavoine et al., 1998; Russel and Model, 1982), with the $\mathrm{N}$-terminal portion in the periplasm and the C-terminal tail in the cytoplasm (Vos et al., 2009; Wickner, 1975). A number of physico-chemical methods for the investigation of membrane protein dynamics have been 


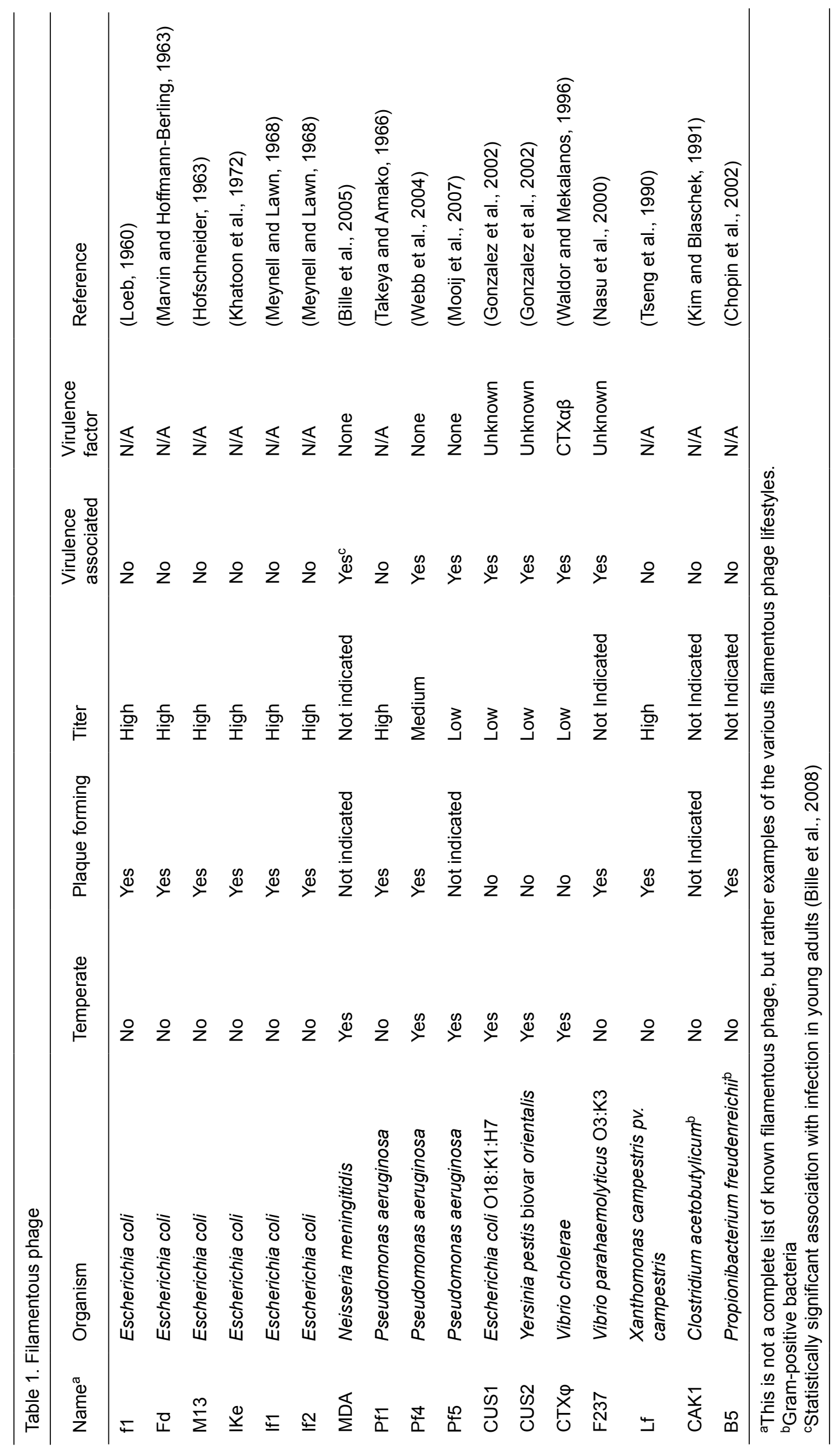


tested on Ff pVIII as a model (Hemminga et al., 2010) and more recently solid-state NMR has been used to resolve the structure of $\mathrm{pVIII}$ of $\mathrm{Ff}$ and $P$. aeruginosa phage Pf1 in membranes and the virions (Goldbourt et al., 2010; Opella et al., 2008; Park et al., 2010).

In the virion, the negatively charged N-terminal 4-5 residues are disordered. The remaining part of $\mathrm{pVIII}$ is a slightly curved $\alpha$ helix, at a small angle to the virion axis.
In Ff pVIII, the $\alpha$ helix is amphipathic down to the $20^{\text {th }}$ residue and then hydrophobic to residue 39 , ending with a 10-residue positively charged helix that interacts with encapsulated DNA (Figure 1A; Marvin et al., 2006). This hydrophobicity and charge arrangement is the conserved in pVIII of other filamentous phage (Marvin, 1998). Thousands of $\mathrm{pVIII}$ subunits are held together through hydrophobic interactions, in a helical arrangement that is reminiscent of

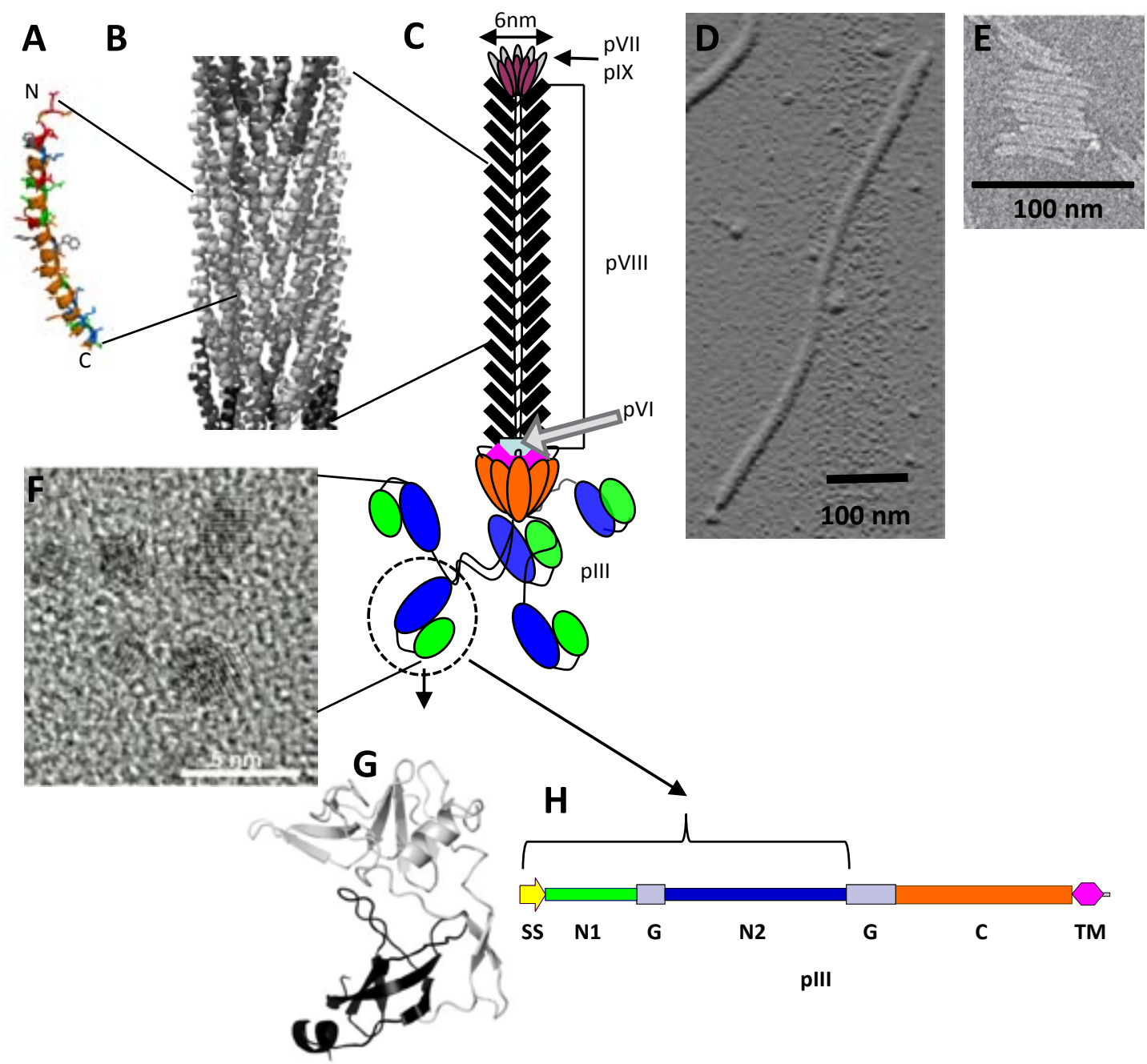

Figure 1. The Ff virion. A. Model of a pVIII monomer showing hydrophobic residues (green), hydrophilic residues (orange), positively charged residues (blue), and negatively charged residues (red). N and C termini of pVIII are indicated. B. Ribbon representation of the pVIII arrangement within the filamentous phage capsid. PVIII within the capsid forms a shingle-like array of helices. C. Schematic representation of the virion. D. Atomic force microscope image of Ff virion (M. Russel and P. Model, sample prepared by J. Rakonjac). E. Electron micrograph of microphage (kindly provided by James Conway and Dalaver $\mathrm{H}$. Anjum, microphage sample prepared by Bennett and Rakonjac, unpublished). F. High-resolution TEM lattice fringe images of five $\mathrm{ZnS}$ nanocrystals at the plll-end of a single Ff virion. From Lee et al. (2002), reprinted with permission from AAAS. G. Ribbon representation of the N1 domain (dark gray) and the N2 domain (light gray) of plll. The high glycine linker sequence located between the $\mathrm{C}$-terminus of the $\mathrm{N} 1$ domain and the $\mathrm{N}$-terminus of the $\mathrm{N} 2$ domain is flexible and hence is not visible in this structure. H. Domain organization of plll preprotein. SS, signal sequence, N1, N2, C, domains of plll; G, glycine-rich linkers; TM, transmembrane helix.

The images of the pVIII subunit (A), the capsid (B), and the N1-N2 domains of plll $(G)$ were derived from coordinates of the RCSB PDB database accession numbers 2cOw (Marvin et al., 2006) and 1g3p (Lubkowski et al., 1998), respectively, using PyMOL (DeLano, 2006). 
snake-skin scales (Figure 1B). The structure of pVIII and the virion is conserved among analyzed filamentous phage (Day et al., 1988; Marvin, 1998); however there are two different classes of symmetries of the helical virion. In E. coli phage $\mathrm{Ff}$, IKe and If1,(class I), pVIII subunits are arranged on a five-start helix with 2-fold screw axis $\left(\mathrm{C}_{5} \mathrm{~S}_{2}\right.$ symmetry) of about $32 \AA$ pitch, with five subunits in each "ring" of the virion tube, related by a 5-fold rotation axis (Caspar and Makowski, 1981; Marvin et al., 2006). In the phage of Pseudomonas and Xanthomonas (class II) pVIII subunits are arranged on a simple one-start helix of $\sim 15 \AA$ pitch, with 5.4 subunits per turn $\left(\mathrm{C}_{1} \mathrm{~S}_{5.4}\right.$; Caspar and Makowski, 1981; Goldbourt et al., 2007).

The set ratio of subunits per nucleotide in $\mathrm{Ff}$ is $0.42 \pm$ 0.01 (Newman et al., 1977) whereas in Pf1 it is exactly 1 (unity; Wiseman and Day, 1977). The DNA conformations in the two classes differ greatly although both DNA helices are right-handed. In Ff, the bases are stacked at the center with the phosphates on the outside interacting with the capsid; the bases from opposing sides of the single-stranded DNA circle are $\mathrm{H}$-bonded to one another, but only about $25 \%$ of the $\mathrm{H}$-bonding can be of the Watson-Crick type (Day et al., 1988). In Pf1, the two sides of the single-stranded DNA circle are so highly stretched and twisted that the sugar phosphate back-bones are in contact with each other at the center and the bases are exposed on the outside for interaction with the capsid; the bases are so widely separated from each that $\mathrm{H}$-bonding is not possible (Liu and Day, 1994; Tsuboi et al., 2010). Other filamentous phage have yet other DNA conformations.

Given that the length of a virion is determined by the size of the DNA and its particular conformation as maintained by the capsid, inserting or deleting DNA is a simple way to control the length of the virion. While the wild-type Ff phage is normally $\sim 900 \mathrm{~nm}$ long, the shortest virion that can be assembled is only $50 \mathrm{~nm}$ in length (Figure 1E; see below in the "Ff replication" section; Specthrie et al., 1992). Aside from the size of packaged DNA, the length of the virion

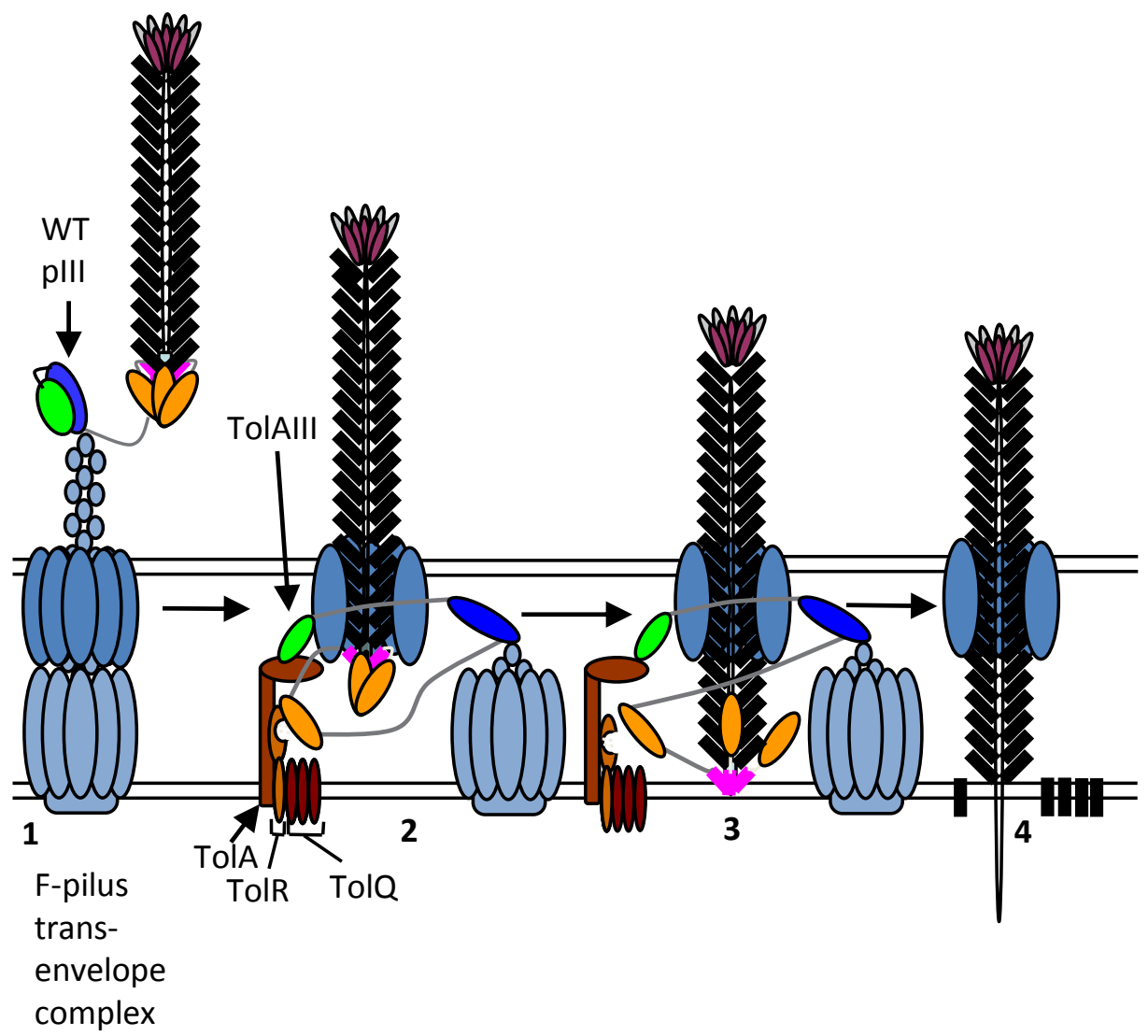

Figure 2. Model of Ff phage infection. (1) Binding of N2 domain (dark-blue oval) to the tip of the F-pilus (light-blue circles) and pilus retraction. (2) Binding of N1 domain (bright-green oval) to TolA III domain (brown oval). (3) "Opening" of the C-domain and insertion of the C-terminal hydrophobic helix into the inner membrane. (4) Entry of phage DNA into the cytoplasm and integration of the major coat protein pVIII into the inner membrane. Steps 1 and 4 are based on published findings, whereas steps 2 and 3 are speculative. Symbols: OM, outer membrane; IM, inner membrane. plII N1 domain, dark-blue oval; pllI N2 domain, bright-green oval; pllI C domain, orange oval; plll C-terminal hydrophobic helix (membrane anchor), pink rectangle; pIII glycine linkers, gray lines; major coat protein pVIII, black rectangles; pVII, gray ovals, pIX, purple ovals; TolA and ToIRQ, brown shapes; F-pilus, and the trans-envelope pilus assembly/retraction system, light-blue. The phage contains 5 copies of pIII, but for simplicity only one full-length pllI is shown. However, this is consistent with experimental data: N1N2 and C domain operate "in cis" and fewer than five functional copies are sufficient for infection (Bennett and Rakonjac, 2006). 
depends on the relative efficiency of initiation or termination to elongation. In $\mathrm{Ff}$ mutants of the minor proteins that initiate $(\mathrm{pVII} / \mathrm{plX}$ ) or terminate ( $\mathrm{plII} / \mathrm{pVI}$ ) assembly, extremely long virions that carry sequentially packaged genomes are produced, more twenty-fold in length compared to wild-type virions (Lopez and Webster, 1983; Rakonjac and Model, 1998).

\section{Minor virion proteins: $p V I I, p I X, p I I I, p V I$}

In contrast to the detailed knowledge of pVIII structure and packing along the filament, no structural information is available for the two caps. Proteins pVII and pIX are incorporated into the virion at the initiation step of assembly and are the first to be extruded from the cell (Fig 1C; (Endemann and Model, 1995; Grant et al., 1980). Both are small hydrophobic proteins of only 32 (pVII) and 33 (plX) amino acids; they are inner membrane proteins prior to assembly, but in Ff phage they do not contain a signal sequence and are thought to spontaneously insert into the membrane (Endemann and Model, 1995). The structure of these two proteins has not been solved and their arrangement in the virion has not been determined. Genetic analysis showed that the residues near the $\mathrm{C}$-terminus are involved in interactions with the packaging signal, a DNA hairpin that targets phage genome for packaging (Russel and Model, 1989). The sole clue about the accessibility of these two proteins is their ability to display peptides and proteins fused to their $\mathrm{N}$-termini. For both proteins, once an addition to the $\mathrm{N}$-terminus has been made, a signal sequence is required for successful incorporation of these chimeric proteins into the virion and display on the surface of the virion (Gao et al., 1997; Gao et al., 2002; Huang et al., 2005).

Proteins pllI and $\mathrm{pVI}$ are added to the virion at the end of assembly. They form a distal "cap" of the filament and at the same time release the virion from the cell (Rakonjac et al., 1999; Rakonjac and Model, 1998). These two proteins are required for the structural stability of the virion and also for termination of assembly. In addition, plll mediates entry of the phage into the host cell (Figure 2). Both plll and pVI are integral membrane proteins (Boeke and Model, 1982; Endemann and Model, 1995).

The structure of the pllI-pVI complex in the virion cap is not known. Direct evidence for the number of plll subunits per virion has been provided recently as a by-product of a nanotechnology application, in which ZnS nanocrystals were nucleated by $\mathrm{N}$-terminally displayed peptides (Lee et al., 2002). The TEM of the nanocrystal-decorated virion tip shows five ZnS nanocrystals associated with the tip of the virion, corresponding to five copies of plll (Figure 1F). Since $\mathrm{pVI}$ and plll are equimolar in the virion cap (Grant et al., 1980 ), there must be five $\mathrm{pVI}$ subunits per virion. Thus the distal cap maintains the fivefold axial symmetry of the pVIII arrangement along the virion filament.

$\mathrm{PVI}$ is a 112-residue, mostly hydrophobic protein. It is integral membrane protein prior to assembly into the virion (Endemann and Model, 1995), predicted by the TMHMM2.0 (Krogh et al., 2001) to contain three transmembrane $\alpha$ helices, with the $\mathrm{N}$ terminus in the periplasm and the $\mathrm{C}$ terminus in the cytoplasm. At 406 amino acids in length (424 residues including signal sequence), plll is distinctly larger than the other four virion proteins. PIII is composed of three domains (N1, N2 and $\mathrm{C}$ ) separated by long glycine-rich linkers (Figure $1 \mathrm{C}, \mathrm{G}, \mathrm{H}$ ). Prior to assembly into the virion, plll is targeted to the inner membrane by its $\mathrm{N}$-terminal signal sequence and anchored in the phospholipid bilayer by a C-terminal hydrophobic transmembrane $\alpha$ helix, in a SecYEG and SecA-dependent manner (Boeke and Model, 1982). Given the C-terminal position of the membrane anchor, most of plll is localized in the periplasm prior to assembly into the virion; only five C-terminal residues are located in the cytoplasm (Davis et al., 1985; Davis and Model, 1985).

The N1 and N2 domains of plll interact with the host receptors; the structure of these two domains has been determined using X-ray crystallography and NMR (Figure 1G; (Holliger et al., 1999; Lubkowski et al., 1998). The three-dimensional structure of the $\mathrm{C}$ domain, which is required for termination of phage assembly, formation of a detergent-resistant virion cap and for late steps in phage infection, is yet to be determined (Bennett and Rakonjac, 2006; Rakonjac et al., 1999). An antibody specific for the C-terminal 10 residues of plll cannot bind to plll when it is in the virion (Rakonjac, unpublished). Therefore, this C-terminus must be buried within the virion cap, which is composed of the pllI C-domain and pVI.

\section{Life cycle}

Filamentous phage adhere to either of two major life styles - exclusively episomally replicating phage or temperate phage that are chromosomally integrated, but can be induced to start episomal replication; Table 1). Episomally replicating filamentous phage (e.g. Ff and Pf1) produce large numbers of progeny phage, reaching titers of up to $10^{13}$ per $\mathrm{mL}$ of culture. In contrast, many chromosomally integrated phage are very low producers, releasing only 1 phage per $10-100$ cells under the inducing conditions (Davis et al., 2002). However, this is not the rule; temperate phage of Xanthomonas can produce $10^{11}$ phage per $\mathrm{mL}$ of culture upon switching to a poorly understood "virulent" mode of growth (Kuo et al., 1994). The replication and gene expression of episomally replicating filamentous phage (e.g. Ff or Pf1), once they infect the host cell, proceeds unabated; their genomes do not encode regulatory proteins. In contrast, gene expression and replication of chromosomally integrated filamentous phage is tightly controlled. These phage encode transcriptional regulators whose role is to inhibit transcription of the replication protein and downstream virion genes (Waldor and Friedman, 2005).

\section{Infection}

The primary receptors for filamentous phage are pili, long filamentous structures on the surface of bacterial cells. Three types of pili can serve as primary receptors, including conjugative $\mathrm{F}, \mathrm{N}$ (or I) and type IV pili (Campos et al., 2003b; Deng et al., 1999; Endemann et al., 1992; Holland et al., 2006; Jouravleva et al., 1998; Waldor et al., 1997; Yang et al., 2004). The secondary receptor for phage as diverse as $E$, coli $\mathrm{Ff}$ and $V$. cholerae $\mathrm{CTX} \varphi$ is the TolQRA complex of inner membrane proteins, highly conserved in Gramnegative bacteria (Click and Webster, 1997; Heilpern and Waldor, 2000). TolQRA belongs to a larger trans-envelope Tol-Pal complex involved in cell division and maintenance of cell envelope integrity (Cascales et al., 2007; Gerding et al., 2007). 
The largest virion protein, plll, described in the previous section, mediates infection of the host (Figure 2). Its two $\mathrm{N}$-terminal domains bind to the primary and secondary receptors and its $\mathrm{C}$-domain is involved in virion uncoating and DNA entry into the host cell cytoplasm (Bennett and Rakonjac, 2006; Deng and Perham, 2002; Reichmann and Holliger, 1997). plll is the most diverse virion protein among filamentous phage, often with no significant homology between the counterparts from distant phage. This is puzzling, given that distantly related phage can use highly conserved ToQRA complex for plll-mediated infection and entry. The gene (glli) can nevertheless be identified based on its size and position in the genome.

The organization and order of the two N-terminal receptor-binding domains can differ even between closely related phage. For example, plll of $E$. coli phage IKe, which binds to the $\mathrm{N}$ (or I) pili, has no glycine-rich linker between the two $\mathrm{N}$-terminal domains, and the order of the two domains is switched relative to $\mathrm{Ff}$ phage (Endemann et al., 1992). In Ff phage, the N2 domain binds to the primary receptor, the tip of the $F$ (or conjugative) pilus, whereas the $\mathrm{N} 1$ domain binds the periplasmic domain III of TolA; the opposite is true for IKe pllI. Binding to the F pilus induces a conformational change by cis-trans isomerization of $\mathrm{PrO}_{213}$ within the N2 domain (Eckert et al., 2007). This releases the $\mathrm{N} 1$ domain from the $\mathrm{N} 2$ domain, exposing the TolA binding site on the N1 domain (Eckert et al., 2007; Lubkowski et al., 1999; Reichmann and Holliger, 1997). If the F pilus or the F-pilus-binding domain of plll are absent, the infection efficiency decreases by several orders of magnitude, but is not completely abolished; in contrast, TolQRA and the cognate plll domain are absolutely required for infection (Click and Webster, 1997, 1998; Reichmann and Holliger, 1997; Russel et al., 1988).

A common characteristic of pili that serve as primary receptors for filamentous phage is the ability to retract towards the cell surface, bringing the filamentous phage close to the secondary receptor located in the periplasm (Lawley et al., 2003; Maier, 2005). It had been thought that the retraction of the $F$ pilus was induced binding of the Ff phage, however recent evidence shows that the $F$ pilus undergoes spontaneous oscillatory extension and retraction cycles (Clarke et al., 2008). The events that follow pilus retraction and allow plll to gain access to TolA are unknown, simply because the mechanics of the F pilus conjugative machine is poorly understood. Pilus retraction, followed by a set of unknown events, somehow ushers plll (and presumably the virion cap) across/through the outer membrane and into the periplasm, where the $\mathrm{N} 1$ domain can interact with the periplasmic domain of TolA (Lubkowski et al., 1999; Reichmann and Holliger, 1997). The postreceptor binding steps of infection are also unknown. All three proteins of the TolQRA complex, and a functional pIII C-domain covalently linked to the N1N2 domains, are absolutely required for phage infection, which ultimately results in entry of the phage ssDNA into the cytoplasm and integration of the major coat protein into the inner membrane (Bennett and Rakonjac, 2006; Click and Webster, 1997; Smilowitz, 1974; Trenkner et al., 1967). C domain of plll is predicted to be $\alpha$-helical; three C-terminal helices (two amphipathic and the third, hydrophobic anchor) are required for phage entry (Bennett et al., 2011). The organization of a helices in the $\mathrm{C}$ domain resembles $\alpha$-helical pore-forming toxins; this is supported by threading using the algorithm I-TASSER (Zhang, 2008), which selected the membrane insertion domain (domain T), of diphtheria toxin as the top ranked template for modeling of the $\mathrm{C}$ domain (Choe et al., 1992).

Interestingly, expression of plll N2 domain alone in $\mathrm{F}^{+} E$. coli abolishes conjugation as well as infection with another F-pilus-specific phage (small ssRNA phage f2 or MS2) that binds along the sides of the pilus. These two phenotypes are suggestive of plll-mediated pilus assembly inhibition (Boeke et al., 1982). Given that the F-pilus is up to $4 \mu \mathrm{m}$ in length, inhibition of its assembly by the N2 domain is strategically very important to securely dock the virion to the host cell envelope and make the infection irreversible.

A number of filamentous phage use retractable type IV and conjugative $\mathrm{N}$ (or I) pili for infection, but little is known about their receptor-plll interactions. Interestingly, the type IV pili are evolutionarily unrelated to the conjugative pili (including $\mathrm{F}$ and $\mathrm{N}$ ) and completely different in the mode of their assembly and in morphology, hence the plll-pilus interactions in phage that utilize them as primary receptors are likely very different from those of $\mathrm{Ff}$. An approach using chimeric plll molecules showed that the primary receptorbinding domain (N2) of pllI from phage IF1 and CTX $\varphi$ allow $\mathrm{f} 1$ to infect the I-pilus containing $E$. coli and TCP piluscontaining $V$. cholerae, respectively (Heilpern and Waldor, 2003; Lorenz et al., 2011). The efficiency of infection, mediated by chimeric plll proteins, however, decreases by several orders of magnitude if the distance between the three domains (N1, N2 and $\mathrm{C}$ ) is changed by inserting additional domains (Heilpern and Waldor, 2003; Marzari et al., 1997). Despite very low N1 domain conservation, these phage use the conserved TolA protein as a secondary receptor, and this appears to be sufficient to trigger plll ${ }_{\mathrm{Ff}} \mathrm{C}$ domain-mediated entry.

\section{Replication}

Following entry into the host cell, the ssDNA genome of episomally replicating and temperate phage have two different fates, the former entering replication and the latter integrating into the chromosome. Interestingly, both of these processes rely on the enzymes that normally act on doublestranded DNA: RNA polymerase for replication of the negative strand and XerC recombinase for chromosomal integration. In both of these situations, locally folded ssDNA forms quasi-double-stranded binding sites for the appropriate proteins: -35 and -10 boxes for RNA polymerase (Higashitani et al., 1997) and dif sites for the site-specific XerCD recombinase (Val et al., 2005).

\section{Ff replication}

The life cycles of episomal filamentous phage are strikingly different from those of chromosomally integrated phage; the genomes of the former phage are also simpler, lacking sequences for host integration and regulation of gene expression (Figure 3; Russel and Model, 2006).

The circular Ff genome, 6,407 nucleotides in length, contains 9 genes, but produces 11 proteins, thanks to internal translational starts within two genes, pll and pl, which give rise to two additional proteins, $\mathrm{pX}$ and $\mathrm{pXI}$, respectively. Phage proteins $\mathrm{pll}, \mathrm{pV}$ and $\mathrm{pX}$, involved in replication, remain in the cytoplasm, whereas all other proteins are targeted to the membranes (Endemann and 


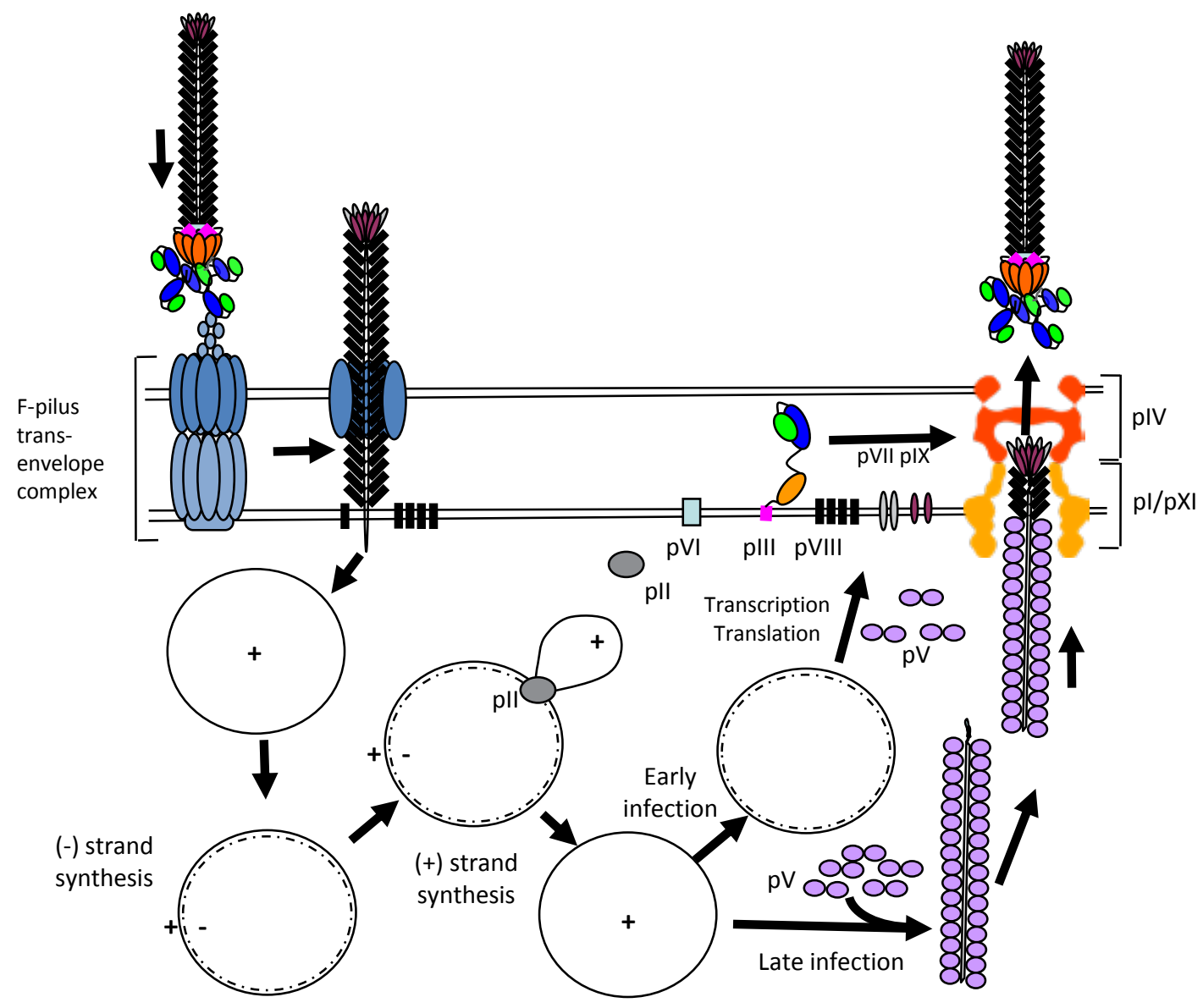

Figure 3. The Ff phage life cycle. Upon infection, the ssDNA (the + strand) enters into the cytoplasm, while the pVIII major coat protein integrates into the inner membrane. Synthesis of the negative (-) strand is initiated at the negative strand origin of replication by RNA polymerase, which generates an RNA primer and is then released from the template (Zenkin et al., 2006). Host DNA polymerase III uses this primer to replicate the complete negative strand. Positive strand synthesis is initiated by pll (gray circle), which creates a nick in the + strand of the dsDNA replicative for at the positive origin of replication. Supercoiling and formation of a stem-loop structure of the positive (+) origin of replication is required for this step (not shown in the figure). Rolling circle replication then ensues, one strand at a time. During the initial period of viral infection, new positive strands are used as templates for synthesis of negative strands, resulting in an increase in copy number of the dsDNA replicative form (RF). The RF serves as a template for production of phage proteins. Phage proteins II, $\mathrm{V}$ and $\mathrm{X}$ remain in cytoplasm and mediate genome replication and formation of the packaging substrate. Proteins pl, pIV and $\mathrm{pXI}$ form a transport complex spanning the inner and outer membrane (yellow and orange, respectively). Virion proteins pVII, pIX, pVIII, pVI, pIII are inserted into the membrane prior to their assembly into phage particles. Later in the infection, positive strands are coated by dimers of the phage encoded single-stranded DNA binding protein $\mathrm{pV}$ to form the packaging substrate and brought to the cell membrane assembly/export complex (pl/pXI and pIV) for assembly and export. The pIV silhouette is derived from determined cryo-EM structure (Opalka et al., 2003). The structure of the inner membrane complex (yellow silhouette) has not been determined; it is drawn based on the cryo-EM structure of the type III secretion system (Marlovits et al., 2004).

Model, 1995; Marciano et al., 1999; Rapoza and Webster, 1995). The positive and negative origins of replication, as well as the packaging signal or morphogenetic signal, are located in the intergenic region (between gIV and gll).

After entry into the cytoplasm, the Ff ssDNA genome positive (+) strand serves as a template to synthesize the negative (-) strand. This step is independent of phage proteins, and is initiated by host RNA polymerase. The negative origin, which forms two stem-loop structures resembling -35 and -10 promoter sequences, serves as a starting site for host RNA polymerase to synthesize a primer (Higashitani et al., 1997). Following binding to this promoter mimic, the polymerase synthesizes RNA on the ssDNA template, then stalls at a poly- $G$ tract, backtracks and dissociates from the template, leaving an RNA primer of defined length hybridized to the template (Zenkin et al., 2006). Host DNA polymerase III then uses this primer to synthesize the (-) strand of DNA, yielding a double-stranded circle. The negative strand origin is not absolutely required for phage replication. An RNA primer for DNA replication can be synthesized at other locations in the genome, albeit with a lower efficiency (Kim et al., 1981).

The $\mathrm{Ff}$ phage replicate by a rolling-circle mechanism, one strand at a time (Figure 3 ). The dsDNA form of the 


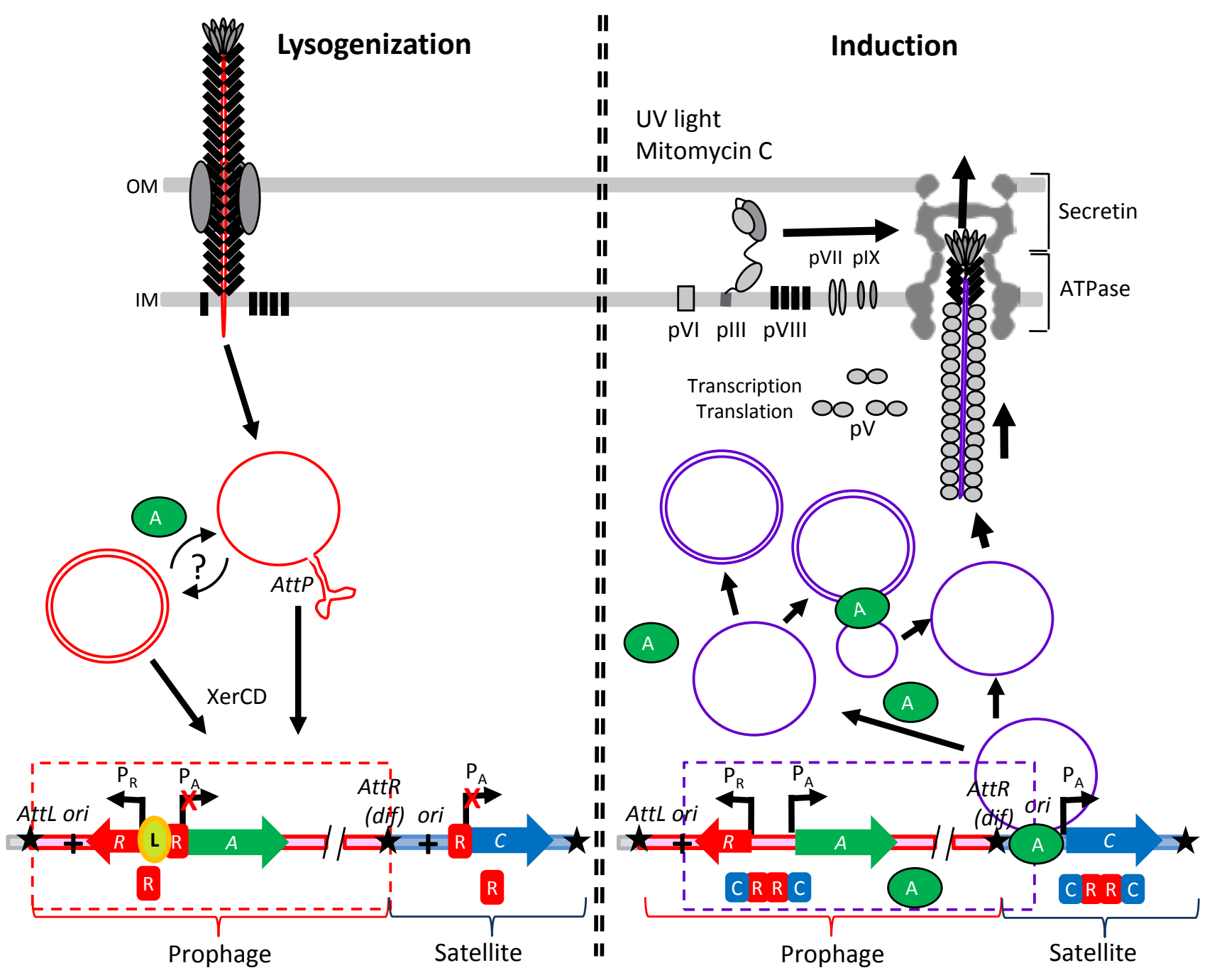

Figure 4. Temperate filamentous phage life cycle. The figure is based on the large body of work on $\mathrm{V}$. cholerae filamentous bacteriophage $\operatorname{CTX} \varphi$ (Davis et al., 2002; Huber and Waldor, 2002; Kimsey and Waldor, 2004, 2009; McLeod et al., 2005; Moyer et al., 2001; Val et al., 2005).

Left panel: entry and lysogenization. After entry into the cytoplasm, ssDNA (red) can either serve as a template to synthesize the (-) strand, resulting in the RF form, or become a substrate for the XerCD recombinase which binds to a forked hairpin loop $(A t t P)$ and mediates site-specific recombination into the dif site located between the chromosomal DNA (gray) and an already inserted satellite phage, e.g. RS1 $\varphi$ or TLC $\varphi$ (blue; Hassan et al., 2010). Given that ssDNA is the substrate for integration and that replication is required for lysogenization, it is likely that not only the $(-)$ strand, but also the $\left(^{+}\right)$strand replication occurs before integration. Replication and/or repair synthesizes the (-) strand of $\operatorname{CTX} \varphi$, forming a prophage (pink) flanked by the modified dif site $(A t t L)$, reconstituted dif site $(A t t R)$, followed by the satellite or defective prophage (blue). Expression of negative regulator RstR (red, labeled "R") and its binding to the regulatory sequences between two divergent promoters $\left(P_{R}\right.$ and $P_{A}$ ) in combination with chromosomally-encoded LexA (yellow, labeled "L"), inhibits transcription of the replication protein RstA (green, labeled "A"), genes encoding other phage proteins (not shown) and the positive regulator RstC encoded by the satellite (blue, labeled "C"), while stimulating its own expression.

Right panel: induction, replication and phage assembly. Upon induction of the SOS response by UV or Mitomycin C, LexA becomes degraded. As a consequence, the $\mathrm{P}_{A}$ promoter transcription and production of the replicator $(A)$, positive regulator $(C)$ is and other prophage genes transcribed from this promoter are induced. $C$ sequesters $R$, preventing $P_{A}$ promoter repression. Replication of prophage is initiated from (+) origin of replication (ori) which is located $\sim 500$ nucleotides downstream from the Att $L$ site, and proceeds until it reaches the ori of the satellite, synthesizing new $(+)$ strand and releasing the recircularized old $(+)$ strand ssDNA, a combination of the prophage and satellite, between two (+) origins of replication. Therefore, the resulting replicon (purple) is not the same as the one that was integrated into the chromosome (red). The episomal replication ensues, producing the $(+)$ ssDNA which is packaged into the virion and secreted out of the cell. 
Ff phage genome is often referred to as the replicative form (RF), whereas the positive $(+)$ strand ssDNA form of the genome is referred to as the infective form (IF). The replicative form serves as a template to synthesize the (+) strand and for transcription of the phage genes.

The (+) strand origin of replication is absolutely required for phage DNA replication and packaging. The product of the replication cycle initiated from this origin is the circular ssDNA that is packaged into the virion. PII, the replication protein, binds to a stem-loop structure in the positive origin formed in supercoiled RF, cleaves the positive strand at a set site and covalently binds to the 5' end (Asano et al., 1999; Greenstein et al., 1988; Horiuchi, 1997). The cleavage of the $(+)$ strand by pll leaves a free $3^{\prime}$ end that serves as a primer for host DNA polymerase III which synthesizes the new $(+)$ strand (Meyer and Geider, 1982). The old (+) strand is displaced as the new one is synthesized. When a circle is complete, the covalently linked pll cuts the displaced $(+)$ strand at the junction between the old and newly synthesized DNA and re-ligates the two ends together in a strand-transferase reaction that liberates pll (Asano et al., 1999). Early in infection the newly synthesized (+) strands are used as a template for (-) strand replication, increasing the copy number of dsDNA to about 50 per cell and in turn increasing the synthesis of phage-encoded proteins. Later in the infection when the concentration of phage proteins has increased, (+) strands are coated by ssDNA-binding protein $\mathrm{pV}$, with the exception of a hairpin loop that serves as a packaging signal. The ssDNA-pV complex is a packaging substrate for phage assembly. $\mathrm{pV}$ has an additional regulatory role - it inhibits translation of pll (Michel and Zinder, 1989). This regulatory loop serves to coordinate ssDNA production and packaging.

The packaging or morphogenetic signal targets the ssDNA-pV complex to the $\mathrm{pl} / \mathrm{pXI} / \mathrm{pIV}$ phage export complex and assists the minor proteins $p \mathrm{VII}$ and $\mathrm{pIX}$ in identifying phage ssDNA genomes so that they can be packaged into virions and exported (Russel and Model, 1989). Only the packaging signal on the positive strand is recognized and packaged (Zinder and Horiuchi, 1985). It has been noted, however, that the export system packages ssDNA of Ff mutants that do not contain the packaging signal as well as unrelated plasmid ssDNA, albeit at a low efficiency (Russel and Model, 1989).

In Ff filamentous bacteriophage, some truncated virions are produced, often after about 40 passages of the phage through host cells in the absence of clonal (plaque) purification, when genomes containing spontaneous duplications of the replication origin tend to appear in the culture (La Farina et al., 1987). In these spontaneous double-origin genomes, $(+)$ strand replication is initiated at the origin 1 (ori1); when the replication fork reaches the next positive origin 2 (ori2) the termination signal is recognized by pll, which makes another cut and then ligates the two ends of the $(+)$ strand, to create a small genome spanning the segment between ori1 and ori2. Given that virion length is determined by the size of packaged ssDNA, the resulting virions are relatively short. This small replicating segment interferes with full-length genome replication and packaging, the short virions becoming a significant fraction of the phage progeny. This property has been used to engineer a "microphage"-producing template - a plasmid containing the packaging signal flanked by two positive origins, of which the second functions only as a terminator. When cells containing this plasmid are infected with an interference-resistant helper phage (R474), the (+) strand replication between the two origins results in a 200nucleotide "genome" that is packaged into a $50 \mathrm{~nm}$-long particle (Figure 1E; Specthrie et al., 1992).

Temperate filamentous phage - chromosomal integration and replication

The genomes of temperate or lysogenic filamentous phage integrate into dif sites on the host chromosome (Figure 4); this event is dependent on the host site-specific dif-site binding recombinase, XerCD, which normally serves to resolve dimers of chromosomes (Huber and Waldor, 2002). The phage genome contains two inverted repeats of the dif site that form a forked stem-loop structure, thus reconstituting a double-stranded XerCD binding sequence in the ssDNA (Val et al., 2005). The action of XerCD recombinase on this secondary structure results in site-specific recombination and insertion of the phage genome into the dif site of the chromosome. In $V$. cholerae, duplicate $\operatorname{CTX} \varphi$ genomes are inserted into the same dif site, suggesting that at least one round of each (-) and (+) strand replication precedes integration (Davis and Waldor, 2000). Interestingly, the complex integrated element that contains the $\mathrm{CTX} \varphi$ genome, including ct $x A B$ genes (encoding Cholera toxin, CtxAB), was likely generated during the evolution of two recent pandemic strains through successive integration events that include, besides $\operatorname{CTX} \varphi$, two types of satellite filamentous phage, RS1 $\varphi$ and TLC $\varphi$ (Hassan et al., 2010). Replication and assembly of these two satellite phage depend on "helper" phage - RS1 $\varphi$ on $\operatorname{KSF} \varphi$ or $\operatorname{CTX} \varphi$, and $\operatorname{TLC} \varphi$ on fs $2 \varphi$. V. cholerae strains containing successive lysogenization stages can be found in Nature, and these can also be recreated in the laboratory (Campos et al., 2003b).

After lysogenization, the integrated $\mathrm{CTX} \varphi$ phage genomes are inactive in replication and virion genes are not transcribed due to the presence of a regulatory circuit involving a combination of host, phage and satelliteencoded regulatory proteins (Figure 4; Davis et al., 2002; Kimsey and Waldor, 2009; Waldor and Friedman, 2005). The absence of virion gene expression, particularly lack of plll (which in Ff phage blocks the TolQRA secondary receptor complex), likely allows super-infection to occur, making successive lysogenization events possible. In contrast to genes encoding proteins that are required in the viral life cycle, the "passenger" toxin genes ( $\operatorname{ct} x A B)$ within $\mathrm{CTX} \varphi$ genome contain additional regulatory sequences that allow their independent regulation by a chromosomallyencoded environmentally-controlled tox $R$ regulon (Childers and Klose, 2007).

The same set of stresses that induces the lytic cycle in the "standard" tailed temperate or lysogenic phage (e.g. $\lambda)$ also induces replication in filamentous phage lysogens through a regulatory circuit that involves induction of SOS response and degradation of LexA protein (Quinones et al., 2005). The consequence of this induction, in contrast to that of tailed phage, is not genome excision and cell lysis. Rather, expression of a replicator protein (RstA in $V$. cholerae $\mathrm{RS} 1 \varphi$ and $\mathrm{CTX} \varphi$ ) and a positive regulator (RstC in $\mathrm{RS} 1 \varphi$ ) is induced, resulting in a positive feedback loop that sequesters the transcriptional inhibitor, RstR (Davis et al., 
2002). Upon accumulation of the replication protein (RstA), a functional equivalent of $\mathrm{Ff}$ pll, replication of the $(+)$ strand ensues, using the integrated genome as a template. Not only (+) strand, but also double-stranded replicative form (RF) is isolated from the cells after induction, hence the replication occurs both using the chromosomally inserted and episomal DNA as templates (Figure 4; McLeod et al., 2005). In $\operatorname{CTX} \varphi$, the genome is replicated between two origins of replication located in the intergenic sequences flanking the $\mathrm{CTX} \varphi$ coding region, one upstream (derived from the $\mathrm{CTX} \varphi$ genome) and one downstream (derived from the closely related sequentially integrated satellite phage RS1 $\varphi$; Davis and Waldor, 2000; Moyer et al., 2001). V. cholerae strains containing a single chromosomally-integrated filamentous phage genome have never been found in natural isolates. Replication in an engineered strain containing a single $\mathrm{CTX} \varphi$ insertion (and therefore only a single positive origin of replication) only very rarely generated episomal replicons, which were smaller than complete genomes (Moyer et al., 2001). In this dead-end situation, a satellite phage, which could be generated by origin duplication, much like in $\mathrm{Ff}$ phage, could rescue efficient replication and virion production and result in observed composite lysogenic arrays in V. cholerae. In summary, the requirement of two sequentially integrated origins for induction of episomal replication and efficient virion production makes propagation and transmission of $V$. cholerae temperate filamentous bacteriophage a very social affair (Campos et al., 2003a; Hassan et al., 2010). Xanthomonas and Yersinia lysogenic filamentous phage, like those of Vibrio, insert into dif sites (Chouikha et al., 2010; Lin et al., 2001). In contrast, the Pf4 lysogenic filamentous phage of $P$. aeruginosa PA01 does not seem to use dif sites; the replicative form arises by recombination between two direct repeats that flank the Pf4 genome (Webb et al., 2004). Another peculiarity of Pf4 is that it encodes a putative reverse transcriptase, which is not found in any other lysogenic filamentous phage genome.

Some lysogenic phage, including $\mathrm{CTX} \varphi$, are produced at very low levels after induction - up to $10^{5}$ per $\mathrm{mL}$ (Quinones et al., 2005). Others, like Xanthomonas campestris Cf16 and $P$. aeruginosa lysogenic phage $\mathrm{Pf} 4$, achieve much higher titers. These two phage have rather dynamic regulation of virion production, which seems to be tuned with the age of the cell lawn (Cf16) or the biofilm (Pf4); (Dai et al., 1987; Rice et al., 2009). P. aeruginosa PA01 growing in biofilms assemble and release Pf4 phage continually; however, on about day 4 of biofilm growth, the phage release intensifies (titer increases from $10^{7}$ to $10^{9}$ per $\mathrm{mL}$ ). These new virions represent a different entity, named "superinfective" phage. These late-released "superinfective", but not the earlyreleased "regular" phage form plaques on lawns of PA01 (which is a Pf4-lysogen and is resistant to superinfection because of active episomal replication). Both "regular" and "superinfective" phage variants can infect a strain containing a complete deletion of the Pf4 genome (Rice et al., 2009; Webb et al., 2004). The molecular basis of this fascinating phenomenon has not been investigated as yet.

\section{Assembly}

During replication, the newly synthesized circular ssDNA phage genome is covered with dimers of the phage-encoded ssDNA-binding protein, $\mathrm{pV}$, which collapses the DNA into a rod (Figure 3 ). The only exposed segment of the genome is the packaging signal, a hairpin loop. For the assembly to be initiated, the packaging signal must interact with the assembly machinery. Replacement of the $\mathrm{Ff}$ packaging signal with a hairpin loop of different sequence prevents assembly, implying that a sequence-specific component binds to it (Russel and Model, 1989). Further, compensatory mutations for a defective packaging signal were mapped to $\mathrm{pl}$, the inner membrane component of the assembly machinery, and pVII and pIX, the two minor proteins at the end of the virion at which the assembly starts (Russel and Model, 1989). All these data are consistent with a model in which packaging signal recognition by $\mathrm{pVII}, \mathrm{pIX}$ and $\mathrm{pl}$ initiates the assembly. The assembly machine is composed of inner membrane ATPase/channel $\mathrm{pl} / \mathrm{pXI}$ and outer membrane channel pIV, which form the phage assembly "complex" (Feng et al., 1999; Marciano et al., 1999).

The elongation phase of assembly ensues, during which the virion is assembled as it is extruded from the cells. As the ssDNA traverses the membrane, $\mathrm{pV}$ dissociates and is replaced by major coat protein pVIII. When the DNA is completely coated with pVIII, minor coat proteins $\mathrm{pVI}$ and pIII are added to the virion and this event results in the release of the assembled phage from the virion. If either of the two proteins is absent, the phage remain tethered to the membrane (Rakonjac et al., 1999; Rakonjac and Model, 1998). Interestingly, rather than stopping the assembly altogether, the filaments keep elongating by adding new genomes and pVIII monomers, resulting in a bizarre appearance of the infected cell in electron micrographs: after a 90 min infection 200-300 pili-like structures, several micrometers long, emanate from the cell surface.

Deletion analyses have shown that a 93 residue C-terminal fragment of plII, containing one amphipathic helix and the $\mathrm{C}$-terminal hydrophobic helix, is sufficient for release of the phage from the membrane. A shorter C-terminal fragment of 83 residues, lacking the amphipathic helix, incorporates into the filament, but cannot release it from the host cell. These results indicate that a certain minimal portion of the $\mathrm{C}$ domain is required for disruption of the growing filament and release from the cell (Rakonjac et al., 1999), however this fragment is shorter than the one required for phage entry (Bennett et al., 2011). The requirement for incorporation of plll into the virion has been systematically investigated by alanine scanning mutagenesis, which showed that out of 150 residues of the $C$ domain only 24 side-chains, located within the C-terminal 70 residues are required (Weiss et al., 2003). Considering that both plll and $\mathrm{pVI}$ are integral membrane proteins, and that lipids are not found in the virion (Day et al., 1988; Hemminga et al., 2010), it remains puzzling how the assembly machinery mediates the release of these two proteins and the virion becomes excised from the membrane at the end of phage assembly.

Ff production does not kill the cell, but it is a highly coordinated process which coaxes the cell to synthesize and integrate an estimated $10^{6}$ copies of pVIII into the inner membrane per cell per generation. This large burden is relieved through secretion of the virion. If the secretion is blocked by mutating components of the assembly machinery ( $\mathrm{pl}, \mathrm{pXI}$ and $\mathrm{plV}$ ) or proteins involved in the initiation of phage assembly ( $p \mathrm{VII}, \mathrm{pIX}$ ), the host cell accumulates extensive internal mitochondrial-cristae-like folded inner membrane structures and dies (Schwartz and Zinder, 1968). Mutation in the replication protein pll, that prevents synthesis of the 
$(+)$ strand, or sublethal concentrations of the translational inhibitor chloramphenicol rescue from killing (Pratt et al., 1966). Furthermore, a plasmid that expresses all phage proteins, but in which the origin of replication and packaging signal are replaced by a low copy number $\theta$-replication ori (pA15) is not lethal to the host cells (Chasteen et al., 2006). These findings suggest that lowered production of $\mathrm{pVIII}$ in the absence of assembly is tolerated by the host cells.

\section{Secretion machinery}

The inner membrane component of the assembly machinery consists of two proteins, $\mathrm{pl}$ and $\mathrm{pXI}$, the latter corresponding to a C-terminal portion of $\mathrm{pl}$ that is produced by translation from an internal ATG codon within gl. Both pl and pXI are required for assembly (Haigh and Webster, 1999; Rapoza and Webster, 1995). The pl protein (but not pXI) contains a putative ATP-binding domain necessary for assembly. The analysis of pl has been hampered by its high toxicity to the host cell. It is thought that pl can form a channel and it has been shown to have an ATPase activity (Feng, 2000; Horabin and Webster, 1988). A semi-permeable system has been used to show that the ATP is required for Ff assembly (Feng et al., 1997).

pIV, the outer membrane component of the assembly machinery forms a radially symmetrical 14-meric complex upon insertion into the membrane (Opalka et al., 2003). The pIV multimer forms a barrel-like structure with an outer diameter of about $13.5 \mathrm{~nm}$ and height of about 12 $\mathrm{nm}$. The barrel is comprised of three "stacked" rings, an $\mathrm{N}$-terminal ring ( $\mathrm{N}$-ring), middle ring (M-ring) and $\mathrm{C}$-terminal ring (C-ring), with a discontinuous pore in the centre that is interrupted by a septum across the M-ring. The pore diameter ranges from $6 \mathrm{~nm}$ at the $\mathrm{N}$-ring to $8.8 \mathrm{~nm}$ at the C-ring (Opalka et al., 2003). This channel is utilized by the elongating filamentous phage (with a diameter of about 6 $\mathrm{nm}$ ) to cross the outer membrane (Marciano et al., 2001). $\mathrm{N}$-terminal periplasmic portions of the pIV subunits interact with the inner membrane components of the assembly complex, pl/pXI (Daefler et al., 1997; Russel, 1993).

Interest in pIV was intensified by the discovery of homologues in Gram-negative bacteria. These homologues are collectively referred to as "secretins" (Bayan et al., 2006). The secretins are conserved components of otherwise diverse Gram-negative bacterial systems that export proteins and filamentous phage or assemble type IV pili (Figure 5A). Type II systems are utilized for secretion of hydrolytic enzymes and toxins into the extracellular environment (Johnson et al., 2006; Russel, 1998; Sandkvist, 2001). The related type IV pilus biogenesis system is involved in assembly and extrusion of type IV pili, twitching motility and uptake of DNA from the environment (Craig and Li, 2008; Pelicic, 2008). Type III secretion systems translocate proteins directly from the bacterial cytoplasm into eukaryotic cells. Acting together in a coordinated fashion, the translocated proteins manipulate signal transduction and cytoskeleton dynamics within eukaryotic cell, allowing invasion and intracellular growth of bacteria (Block et al., 2008; Coburn et al., 2007; Galan and Collmer, 1999; Moraes et al., 2008).

Characterization of purified wild-type pIV and a "leaky" point mutant by electrophysiology as well as by in vivo experiments established that pIV is a large $(6 \mathrm{~nm}$ in diameter) gated channel that is blocked by the assembling phage filament (Marciano et al., 1999; Marciano et al.,
2001). A simple septum-like occlusion that interrupts the continuity of the secretin channel has been identified in all of the secretins analyzed thus far by cryo-EM and single particle analysis except the type IV pilus biogenesis system secretin PilQ of $N$. meningitidis, which has a complex plug (Frye et al., 2006). The septum or plug is presumably the gate that maintains the channel in a closed state (Chami et al., 2005; Hodgkinson et al., 2009; Marlovits et al., 2004; Opalka et al., 2003; Reichow et al., 2010). We have recently identified two segments in the centre of the conserved C-terminal secretin family domain that likely form the septum: GATE1 (that spans 39 residues) and GATE2 (that spans 14 residues). GATE1 and GATE2 were identified by selecting for "leaky" mutants able to utilize maltooligosaccharides in the absence of maltoporin LamB. Three additional leaky mutations are located in the region that encodes the periplasmic $\mathrm{N}$-terminal module proximal to the M-ring and could be involved in triggering gate opening (Spagnuolo et al., 2010).

A number of filamentous phage lack the gene for the outer membrane channel, posing the question of how they are extruded through the outer membrane. For two of these phage, СTХ $\varphi$ of Vibrio cholerae (Waldor and Mekalanos, 1996) and MDA $\varphi$ of Neisseria meningitidis (Bille et al., 2005), it was found that each depend on a host-encoded secretin: CTX $\varphi$ utilizes EpsD of the type II secretion system (Davis et al., 2000) and MDA $\varphi$ utilizes PilQ of the type IV pilus assembly system (Bille et al., 2005). The "borrowed" secretin channel EpsD does not require inner membrane components of the type II secretion system in order to secrete CTX $\varphi$ phage (Davis et al., 2000). Hence, EpsD of $V$. cholerae and presumably PilQ of $N$. meningitidis must function with two dissimilar inner membrane secretion components, those of the phage and the type II secretion system or the type IV pilus assembly systems. This is puzzling, given the strict specificity that is normally observed between the $\mathrm{N}$-terminal domains of a secretin and the cognate inner membrane moiety of its trans-envelope secretion machinery. The inner membrane complexes of secretion machineries are believed to energize the transport and presumably to couple secretin channel opening to secretion (Clausen et al., 2009; Craig and Li, 2008; Johnson et al., 2006; Marlovits and Stebbins, 2010). The production of CTX $\varphi$ phage is very low, about one per $10^{3}-10^{4}$ cells, suggesting that the "borrowed" secretin may function at very low efficiency.

\section{Host responses to secretins and filamentous phage infection}

During the highly productive Ff infection (about 1000 phage per cell per generation), accumulation of the major coat protein $\mathrm{pVIII}$ in the inner membrane, together with expression of a few hundred copies of trans-envelope assembly/secretion complexes results in a change in cellular phospholipid metabolism through inhibition of phosphatydilserine synthetase (Chamberlain and Webster, 1978), increased phosphorylation of several proteins including chaperone DnaK (Rieul et al., 1987) and induction of a stress response called the phage shock protein (Psp) response (Brissette et al., 1990; Darwin, 2005; Model et al., 1997).

Originally detected in filamentous phage f1-infected $E$. coli (Brissette et al., 1990), and later identified in a genetic screen for virulence factors in Yersinia enerocolitica (Darwin 

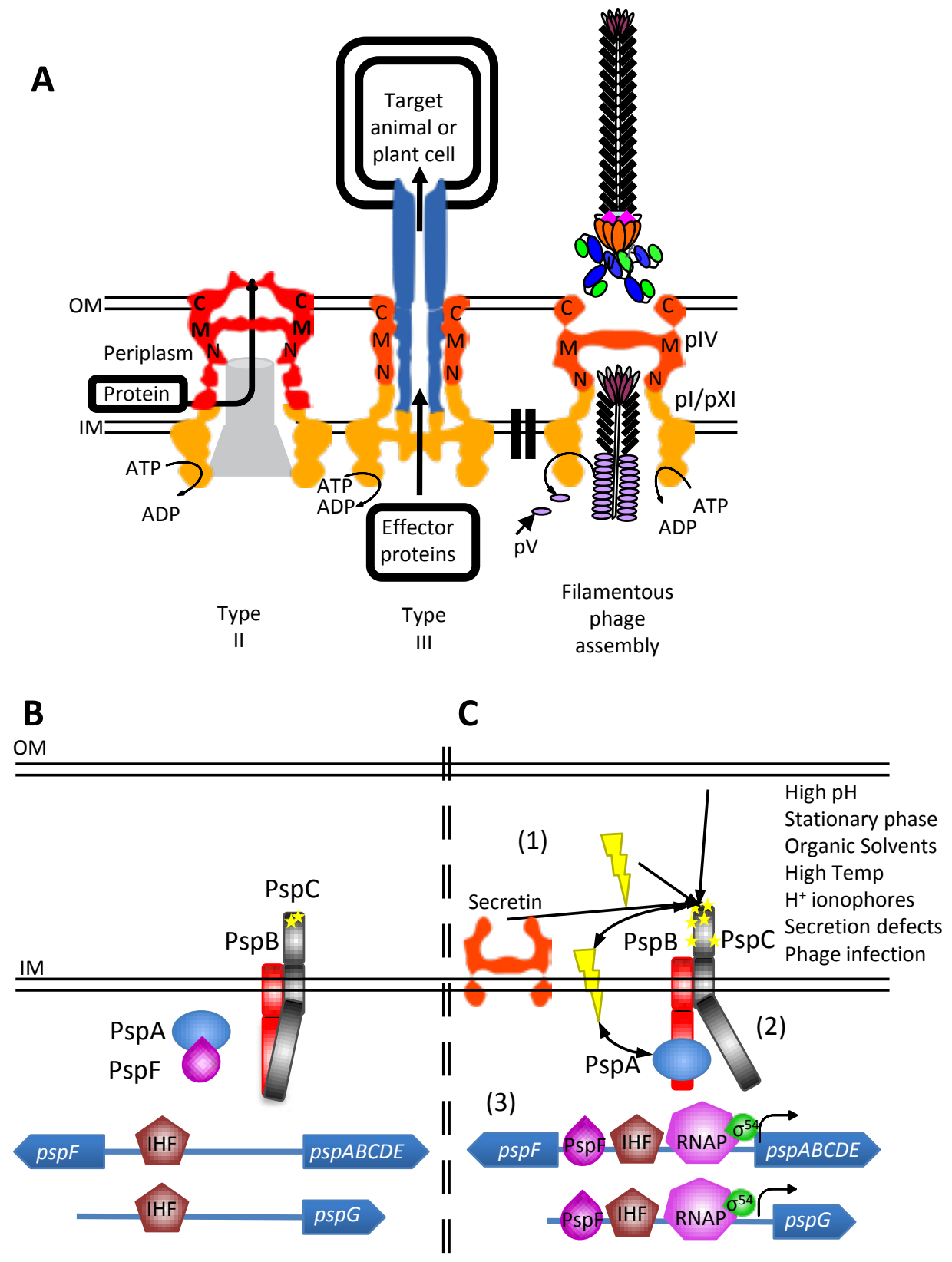

Figure 5. Secretion systems and psp regulon induction. A. Comparison of three secretion systems. IM components vary between systems and species, however some generalities exist. Export is driven by ATP hydrolysis, and each utilise a similar OM component called the secretin (shown in red). Type II secretion substrates enter the secretion apparatus in the periplasm and are exported to the extracellular milieu. Type III secretion substrates enter a molecular needle (blue) threaded through the centre of the secretion apparatus, and are injected directly into target cells. Filamentous phage assembly. The silhouettes of the inner membrane complexes, all drawn in yellow, are based on the cryo-EM structure of the type III secretion system (Marlovits et al., 2004). The structures of the inner membrane complexes of the type II secretion system and the phage assembly system have not been determined. The secretin channels (red silhouettes) were derived from the respective structures obtained by cryo-EM and single particle analysis (Marlovits et al., 2004; Opalka et al., 2003; Reichow et al., 2010). $\mathrm{C}, \mathrm{M}$ and $\mathrm{N}$ denote the respective "rings" recognizable in the cryo-EM structures of secretins. B and C. Induction of the phage shock protein $(p s p)$ stress response regulon. B. In the absence of stress signals, the $p s p$ regulon activator PspF is inactive due to its interaction with PspA. C. The periplasmic domain of PspC detects stresses, inducing the expression of the $p s p$ regulon. Orange shape, pIV or other secretin inserted in the inner membrane; yellow shape, other stresses (listed below the outer membrane). When a stress threshold has been reached (1), a conformational shift in the cytoplasmic domain of PspC occurs, uncovering the binding domain of PspB. PspA then interacts with PspB (2), causing the release of response transcription factor PspF and subsequent transcription of the psp regulon (3); (Gueguen et al., 2009). IM, inner membrane; OM, outer membrane. 
and Miller, 1999), the $p s p$ regulon has been found to encode 7 proteins (PspA-G). pspA-E genes constitute the psp operon; $p s p F$, gene encoding the transcriptional activator of the operon, is located just upstream and is divergently transcribed, while PspG is not linked to the other $p s p$ genes (Figure 5B).

A wide range of stresses induces the Psp response. Upon induction, $\mathrm{PspB}$ and $\mathrm{C}$ have been shown to activate expression of the $p s p$ regulon by releasing $\mathrm{PspF}$ from a complex with PspA (Figure 5C; Gueguen et al., 2009; Joly et al., 2010; Jovanovic et al., 2009; Jovanovic et al., 2010; Maxson and Darwin, 2006). The intermediate events that transduce stress signals to PspB and PspC, however, are unclear and the mechanism of stress relief is not well understood (Darwin, 2005; Jovanovic et al., 2009; Jovanovic et al., 2006; Seo et al., 2007). The accumulation of PspA, the most massively-produced protein of the Psp response, requires hours, in contrast to minutes generally required for accumulation of proteins after induction of bacterial promoters. Given that fast $p s p A$ mRNA accumulation is observed (Spagnuolo et al., 2010), it is possible that posttranslational regulation plays a role in the Psp response. More information about the activation of the CRISPR response (Perez-Rodriguez et al., 2011) as well as genomewide changes in small RNAs, proteome and metabolome or other posttranscriptional and posttranslational processes will likely unlock the secrets of this stress response.

\section{Phage display technology}

Much of the acquired knowledge about Ff filamentous phage replication and structure has been exploited in phage display technology and derived applications in nanotechnology. In 1990/91 first phage display libraries of both peptides and antibodies were published (Barbas III et al., 1991; Clackson et al., 1991; Cwirla et al., 1990; Devlin et al., 1990; Marks et al., 1991; Scott and Smith, 1990), followed by an explosion of phage display use in protein and antibody engineering. Peptide libraries are mainly used to identify motifs to which important cell-signaling proteins bind (e.g. SH3 domain or BiP chaperone; Blond-Elguindi et al., 1993; Cheadle et al., 1994) or to select for agonists of antagonists of the peptide hormones for a receptor of interest (Lowman et al., 1991; Wrighton et al., 1996). Antibody libraries are used to select recombinant "monoclonal" antibodies that bind to potential therapeutic targets, such as antigens present on the surface of malignant cells (Schier et al., 1995). Besides these two major applications, phage display has also been used to select variants of proteins of interest with changed binding target or increased affinity to targets of interest (e.g. protease inhibitors with increased activity (Roberts et al., 1992) or transcription factors with changed DNA recognition sequence; Rebar and Pabo, 1994). The twenty first century brought the new use for Ff phage and phage display - as a toolkit for assembly of nanostructures (Mao et al., 2004).

\section{The principles of phage display}

The aim of all phage display library screenings is to find a rare variant in a library. Once constructed, the library must be screened to isolate the variant of interest. To do so, the phage first must be assembled and released from host cells in sufficient numbers to make it likely that a desired variant is present and can be selected. Success will depend on the affinity of the peptide for the ligand and the number of copies of the peptide per virion. For a library of $10^{10}$ variants, representation of every variant demands that, depending on the expected affinity of interaction, a larger number of particles be screened. This is not a problem, because $\mathrm{Ff}$ used in phage display technology are produced at concentrations (or titers) of up to $10^{13}$ per ml of culture. Increasing the culture volume and concentrating the phage particles further increases this number.

The basic method for affinity screening of the phage display libraries is often referred to as "biopanning" (Parmley and Smith, 1988). The ligand of interest is immobilized on a solid support, and the phage display library (in the form of purified virions) in solution is applied to it to allow binding of specific variants. Multiple rounds of washing are performed to eliminate the adherent non-binders, and what remains bound is eluted. If no specific eluent is available, low or high $\mathrm{pH}$ are commonly used to disrupt interactions of the displayed peptide with immobilized ligand. Because some unspecific binding of phage to the matrix surrounding the ligand occurs, at least three rounds of panning are typically required in order to amplify the binding variants and eliminate the "background" of non-specific binders. However, if several variants of binders are present in the library, the high-affinity variants will outcompete those with low affinity. This could be a problem if, for example, a cDNA library is screened in order to identify the interactome for a ligand of interest, or a peptide library is screened against multiple ligands. Recent reports combined high-throughput sequencing with one or two rounds of panning, to overcome the competition problem and identify a "landscape" of numerous binding variants in a phage display library (Di Niro et al., 2010; Dias-Neto et al., 2009). The readers are referred to phage display manuals for detailed protocols (Barbas III et al., 2001; Clackson and Lowman, 2004; Rodi et al., 2002).

Because of ease of manipulation and exceptional stability of the virions to a broad range of $\mathrm{pH}$ and temperatures, Ff filamentous phage continue to be far more frequently used in phage display technology than tailed phage $\lambda$ and T7. Each of the five $\mathrm{Ff}$ virion proteins have been used as platforms for phage display, but most commonly used are the minor protein plII (Figure 6B-E) and the major protein pVIII (Figure $6 \mathrm{G}, \mathrm{H}$ ). Both proteins in $\mathrm{Ff}$ phage have an essential $\mathrm{N}$-terminally located signal sequence which is required for their targeting to the inner membrane. During translocation, the signal sequence is cleaved by signal peptidase, and the $\mathrm{N}$ terminus of the mature protein is localized in the periplasm. Therefore, to be displayed on surface, proteins need to be inserted, in frame, between the signal sequence and the mature portion of these two proteins.

Small hydrophobic proteins pVII and pIX (Figure 6F) can also serve as a display platform if a signal sequence is provided at the $\mathrm{N}$-terminus of the insert. Moreover, two subunits of a heterodimeric protein can be displayed in pairs in $\mathrm{pVII}$ and $\mathrm{plX}$ in the same host cell, resulting in display of the heterodimeric protein on the surface of the phage (Gao et al., 1999). pVI, the least frequently used protein in phage display, only displays proteins fused to its $\mathrm{C}$-terminus (Jespers et al., 1996).

\section{PVIII display}

In pVIII display, the number of copies of the foreign insert per virion depends on the size of the displayed peptide. The cut-off length for unbiased display of peptides on every 


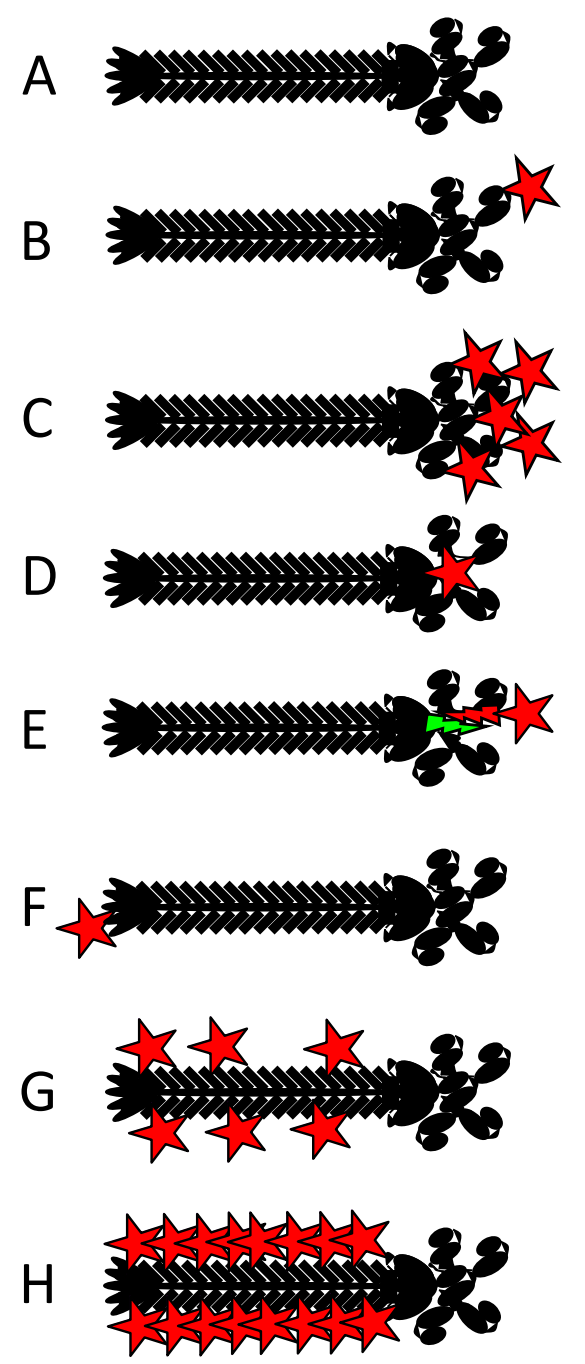

Figure 6. Types of phage display. A, Wild-type phage, B-E, types of plll display: B, monovalent display, with fusions to the full length plli; C, polyvalent display, fusion with the full length pllI; D, monovalent display, with fusion to the $\mathrm{C}$ domain of pllI; $\mathbf{E}$, indirect phage display in which the green and red connecting shapes between the star-shaped displayed protein and truncated plll represent the leucine zipper dimerization domains of transcription factors Fos and Jun; F, pVII and /or pIX display; G, mosaic pVIII display, in which wild-type pVIII is co-incorporated into the virion together with the pVIII fusion. $\mathbf{H}$, uniform pVIII display, in which all pVIII subunits are fused to peptides.

pVIII copy is 6-7 residues (lannolo et al., 1995). In order to display larger peptides and even entire proteins, a wild-type pVIII and display fusions have to be co-assembled into the phage. PVII has also been used for display of heterodimeric protein complexes, by expressing in the same cell two different pVIII fusions which include a cysteine-containing linker. Because pVIII assembles as a dimer, cysteines of the two linkers become covalently linked by an S-S bridge, thereby forming a dimer upon assembly into the virion (Zwick et al., 2000).
PIII display

Only the $\mathrm{C}$ domain is of plll is required for assembly of the virion, hence this domain alone (Figure 6D) can be used in display as long as it is preceded by a signal sequence (Barbas III et al., 1991; Griffiths et al., 1993). Given that $\mathrm{N} 1$ and N2 domains of pllI are required for infectivity of the particles, if truncated pllI is used for display, a wild-type (full length) plll must be provided in order to allow easy amplification of phage. As with pVIII, the inserted sequence must be in frame with the upstream signal sequence and downstream mature (or truncated) plll.

The plll fusions are most commonly expressed from phagemid vectors, which carry both plasmid and $\mathrm{f} 1$ origins of replication, the $\mathrm{f} 1$ packaging signal and an antibiotic resistance gene (Barbas III et al., 2001). The phagemid vectors carry a cloning restriction site between sequences encoding the signal sequence and mature full length or truncated plll. This allows proteins encoded by the inserts to be displayed on the surface of the phage as a fusion with plll. Phagemid DNA into which inserts have been cloned are introduced into $\mathrm{F}^{+}$cells, and upon helper phage infection, the phagemids replicate from the f1 origin, resulting in production of ssDNA that is assembled into the virions displaying the proteins encoded by the phagemids. These virions are usually called phagemid particles or transducing particles (TDP). To amplify a phagemid, the particles are mixed with $\mathrm{F}^{+}$host cells. The phagemid DNA is introduced into the cell by infection, resulting in expression of the antibiotic resistance encoded by the phagemid. In the absence of the helper phage, the phagemid replicates from the plasmid origin of replication.

The phagemid offers flexibility in that the plll fusion for display can be expressed from an inducible promoter. This is desirable because many plll fusions are relatively toxic to the host cell. Furthermore, phagemid vectors are generally smaller than the phage genome, thereby increasing the efficiency of transformation, which is the bottleneck limiting the diversity (or primary size) of phage display libraries. Phagemid phage display vectors also offer flexibility in the number of displayed copies of plll per virion. If wild-type helper phage is used (Figure 6B), there is on average less than one displayed fusion per virion, due to preferential incorporation of wild-type plll encoded by the helper phage. The frequency of display can be increased by using a helper phage with gene III amber ( $\mathrm{glI}^{\mathrm{am}}$ ) mutation in a suppressor strain. The amount of plll expressed from the suppressed

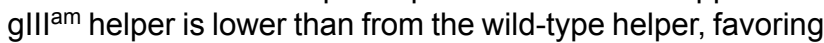
incorporation of phagemid-expressed plll fusion (Oh et al., 2007). For display in all five plll copies (e.g. when libraries are screened for low-affinity interacting partners; Fig 6D), helper phage that carry a deletion of gene III are used (de Wildt et al., 2002; Griffiths et al., 1993; Rakonjac et al., 1997). Recently, a helper plasmid has been constructed, eliminating the need for a helper phage in phage display (Chasteen et al., 2006).

Phage display of antibodies

Antibodies are irreplaceable reagents used in diagnostics and detection of trace amount of substances, from pesticides and hormones to viruses. In the early nineties, phage display technology empowered researchers to use in vitro phage affinity selection instead of immunization and hybridomas, to successfully isolate monoclonal recombinant 
antibodies that recognize the target or antigen of interest. These initial reports showed that when expressed in $E$. coli and assembled into the Ff phage fused to pIII or pVIII, the variable domains of the heavy $\left(\mathrm{V}_{\mathrm{H}}\right)$ and light $\left(\mathrm{V}_{\mathrm{L}}\right.$ and $\left.\mathrm{V}_{\mathrm{K}}\right)$ chains can fold correctly and recognize the cognate antigen (Barbas III et al., 1991; Kang et al., 1991; McCafferty et al., 1990). Two types of display were designed, one in which the heavy and light chain variable domains were expressed as separate polypeptides from the same vector and became associated in the $E$. coli periplasm prior to phage assembly (Fab; Barbas III et al., 1991; Kang et al., 1991), and the other where $\mathrm{V}_{\mathrm{H}}$ and $\mathrm{V}_{\mathrm{L}} / \mathrm{V}_{\mathrm{K}}$ domains were expressed as a single polypeptide chain separated by a long flexible linker (scFv; Clackson et al., 1991). These first antibody libraries were amplified from $B$ cell mRNA of immunized animals or volunteers. However, antibodies against human (self) target proteins, to which humans are naturally tolerant, are crucial targets for therapy. Human antibodies against human antigens have already been obtained by in vitro screening pre-immune phage display libraries of antibodies (Griffiths et al., 1993) and used for development of therapeutic recombinant antibodies (Chames et al., 2002; de Haard et al., 1999; Marks et al., 1991; Schier et al., 1996) and targeting gene delivery to specific human cells (Poul et al., 2000).

Initial screening of human pre-immune libraries yields low-affinity antibodies. However, the affinity can be improved by random mutagenesis of the antibody coding sequence in $E$. coli, or by shuffling variable segments of the selected low affinity antibody with a library of variants in order to find a combination with an increased affinity (Schier et al., 1996; Thompson et al., 1996). The other limitation of pre-immune phage display libraries is their primary size. This limitation was overcome by combining two libraries using in vivo recombination (Sblattero and Bradbury, 2000; Tsurushita et al., 1996; Waterhouse et al., 1993).

Once an antibody with a sufficiently high affinity for the antigen of interest is isolated, it can be expressed independently of the phage in high amounts for clinical use. Moreover, Ff virions displaying antibody variable chain can be used as detection devices or tracers. The scFv-pllI fusions that are displayed on the tip of the phage filament bind the antigen, whereas the filament, which contains over 2000 copies of pVIII, is used for detection of the bound antibody. Anti-pVIII antibodies or fluorophores conjugated to pVIII are used to "flag" the binding sites, thereby allowing immunohistological detection of the antigen (Li et al., 2010; Sobry et al., 2005; Willats et al., 1999; Zhou et al., 2002)

Besides use in diagnostics and therapy, antibodies generated by phage display are also used as catalysts. This application requires immunizing the experimental animal with an organic molecule that mimics the transition state intermediate in a chemical reaction. The antibodies are then displayed on the phage to select for clones that bind to the transition state intermediate and subsequently tested to determine whether they catalyze the reaction of interest (Baca et al., 1997; Fujii et al., 1998; Janda et al., 1997).

\section{Protein evolution by phage display}

Phage display has been a powerful tool for evolution of proteins in the laboratory, to create proteins with novel properties. This is achieved by creating a library of variants of a protein of interest, in which the residues required for binding to substrate or interacting partner are randomized. From that library, a variant binding to a new ligand can be selected. One of the most striking examples of protein evolution is that of zinc finger-containing transcription factors (Rebar and Pabo, 1994). These authors randomized the residues of the zinc finger motif that confer specificity for binding to a certain DNA sequence and then screened the library for binding to a different sequence, to obtain a new zinc finger motif with a changed specificity. Another pioneering example is creation of a variant human growth hormone with increased affinity for the receptor (Lowman et al., 1991). Numerous groups have focused on protease inhibitors, randomizing the protease binding sites in order to achieve increased affinity or changed specificity (Koiwa et al., 2001; Roberts et al., 1992).

Early in the history of phage display technology it was confirmed that the enzymes displayed on the surface of the phage are active (McCafferty et al., 1991). In the following years, sophisticated schemes have been developed to isolate, from randomized libraries, the enzymes that catalyze a reaction of interest. One such scheme is to covalently link a substrate to one copy of plll and the enzyme to another copy of plll in the same particle. Because of the proximity of the substrate, the variant carries out a single turnover reaction to generate a product. The selection scheme is designed so that the product is specifically captured by the solid phase, thereby capturing the enzyme-encoding phage (Forrer et al., 1999; Gao et al., 1997; Hansson et al., 1997; Soumillion et al., 1994).

\section{Phage display cDNA libraries}

Determination of interactions between cellular proteins is a key to understanding the essential cellular processes. The yeast two-hybrid system is most frequently used for this purpose (Fields and Song, 1989). However, the interactions in that system are identified in vivo. The advantage of phage display is that the interactions are selected in vitro, and that the interacting partner (or bait) can be any molecule or molecular complex.

For construction of phage display cDNA libraries, the necessity for the insert to be in frame with both upstream and downstream sequences and in the same orientation as the phage protein to which it is fused effectively decreases the size of the library by a factor of 18 . These odds were improved by designing an indirect display system: the library was fused downstream of a dimerizing leucine zipper domain of the transcription factor Jun, and its interaction partner, Fos, was fused to plll (Figure 6E). The leucine zipper was formed in the periplasm, allowing display of cDNA fusion proteins on the surface of the phage (Crameri et al., 1994). In this setup, fusion of the library inserts to the C-terminus of Fos eliminated the requirement for an in-frame joint downstream of the insert and increased the effective library size from $1 / 18$ to $1 / 6$. This system has been successfully used to identify allergen proteins: phage display cDNA libraries of biological materials that cause the allergy were screened, to identify the protein(s) that induce the allergic reaction. The baits in these screens were $\lg \mathrm{E}$ antibodies of the patients (Crameri and Blaser, 1996). In another approach, a phage display phagemid vector was designed that contains a removable marker cassette (Iox sites-flanked $\beta$ lactamase gene) between the cloning site and glll. Clones containing an open reading frame in correct 
orientation and frame are initially fused to $\beta$ lactamase, conferring resistance to ampicillin to transformed cells. Following selection on ampicillin, helper phage is used to generate the phagemid particles, which are then transfected into a Cre recombinase-expressing host to remove the $\beta$ lactamase cassette by Cre-mediated recombination of lox sites, resulting in fusion of the inserted open reading frame with plll (Zacchi et al., 2003). This method, in combination with two rounds of affinity selection and next generation sequencing, was recently used to identify "interactome", a set of proteins that interact with enzyme transglutaminase 2 (TG2), involved in the regulation of cell growth, differentiation and apoptosis (Di Niro et al., 2010).

Protein fusions displayed on the surface of $\mathrm{Ff}$ are targeted to the periplasmic compartment. This location is unfavorable for folding of many cytosolic proteins, particularly those carrying cysteines, because periplasmic chaperones such as DsbA catalyze formation of S-S bonds, which do not exist in the cytoplasm, and consequently proper folding of the protein is prevented (Bardwell et al., 1991). As the $\mathrm{C}$ terminus of plll is in the cytoplasm, a vector has been constructed for the plll C-terminal display of cytosolic proteins (Fuh and Sidhu, 2000). Another approach to avoid misfolding of cytosolic proteins in the periplasm is to replace the standard signal sequence with a Tat signal sequence. The Tat signal sequence allows translocation of folded protein domains through the inner membrane (Velappan et al., 2010). T7 and $\lambda$ phage, which assemble in the cytosol and therefore eliminate the problem of protein misfolding associated with Ff display, are also used as vectors for the cDNA libraries. Proteins that bind to DNA or RNA sequences of interest, or to chromatin were identified by screening T7 and $\lambda$ phage display cDNA libraries (Cicchini et al., 2002; Danner and Belasco, 2001; Wang et al., 2004).

\section{Phage display of bacterial proteins}

Phage display bacterial genomic shot-gun libraries have been used to identify bacterial proteins that bind to targets of interest. For example, this approach was used to identify and map cell-surface-associated agglutinin, RapA, from the Rhizobium leguminosarum genome (Ausmees et al., 2001). Recently, a Borrelia burgdorferi shot-gun phage display genomic library was used to screen for potential adhesins in the animal (in vivo), resulting in discovery of at least five new adhesion proteins (Antonara et al., 2007). Single-gene phage display libraries were utilized to map a fibronectinbinding motif of the protein FNZ of Streptococcus equi, the IgG- and $\beta 2$-glycoprotein-I-binding domains of protein Sbi of Staphylococcus aureus and many others (Lindmark et al., 1996; Zhang et al., 1999). Recently, two methods for the selective display of bacterial surface and secreted proteins have been designed and used to systematically characterize this group of bacterial proteins. In both, the phagemid vector encodes the C-terminal domain of plII, but not for the signal sequence. Thus, only the inserts that encode signal sequence-carrying proteins in frame with plll are incorporated into the virion. Furthermore, in the absence of plll from the helper phage (if a $\Delta$ gene III helper phage is used), termination of phage assembly and virion release depends on the presence of a signal sequencecontaining insert fused in frame to plll of the cloning vector. Affinity screening for a vector-encoded plll-fused tag (Wall et al., 2003) or direct selection for virion release (Jankovic et al., 2007) were successfully used to obtain clone banks of surface and secreted proteins from Lactobacilli. These phage display clone banks allow functional analyses of individual surface and secreted proteins without a need for systematic cloning, expression and purification. Ff virion is an excellent hapten for immunization (van Houten et al., 2010); hence clone banks of bacterial surface proteins can be used to greatly facilitate screening of vaccine candidates.

\section{Random peptide libraries}

Finding peptide candidates or "leads" for design of organic compounds that bind to a target of interest has been revolutionized by phage display. In pioneering work, (Scott and Smith, 1990) constructed short peptide libraries and screened them for binding to a ligand of interest. Peptide libraries can vary in the length of the peptides they display; furthermore, they can be constrained by formation of a disulphide bond by including two flanking cysteine residues (Felici et al., 1993). A beautiful example of a successful library screen is isolation of a random peptide agonist analogous to erythropoietin, a polypeptide hormone that stimulates erythrocyte proliferation (Wrighton et al., 1996). A multivalent-display linear peptide library was first used to isolate low affinity binding peptides. Building on the consensus derived from this library, a new library of constrained peptides randomized at some of the residues was constructed, displayed at one copy per virion, and used to select a high affinity peptide.

Peptide display has been taken to a new level by applications in cell and tissue targeting as well as receptormediated gene delivery. This was achieved by in situ screening of phage display peptide libraries against cells and tissues to isolate specific cell or tissue binding peptides (Pasqualini and Ruoslahti, 1996). The tissue-binding peptides were isolated by injecting mice with the libraries and recovering the phage from specific tissues of interest, or from human breast cancer tissue xenotransplanted into mice. Such peptides were able to target the transplanted tumor for destruction by fusing the peptide to the cancer drug doxorubicin. In addition to tumor tissue binders, peptide ligands that specifically bind to the vasculature of particular organs such as prostate or kidney have been isolated (Arap et al., 1998). These peptides can be used for therapeutic purposes, for example by fusing them to cytokines or other drugs to concentrate them at the target tissue. This strategy aims to relieve systemic toxicity and/ or increase the efficiency of delivery to the affected tissue. Phage for display of two different peptides on the same particle has been adapted for organ-specific delivery: tissue-specific peptide was displayed as a fusion to plll (at the tip of the phage) while an avidin-binding peptide was displayed as a fusion to pVIII, in 100-200 copies along the phage filament, allowing visualization of phage that binds to the specific ligand via its terminally displayed peptide (Chen et al., 2004).

To adapt $\mathrm{Ff}$ phage for use in receptor-mediated gene delivery, libraries were screened to identify cell-specific internalization-mediating peptides (Burg et al., 2004; Larocca et al., 2002). The selected peptides were not only used for gene delivery, but also for marking or tracking the target cells by expression of phagemid-encoded reporter protein that was imported into the target cell nucleus along with the internalized phage. Finally, high density phage 
display can be used to create diagnostic or tracking devices for biological threat agents, such as spores of the pathogen Bacillus anthracis (Williams et al., 2003).

\section{Bacteriophage as templates for inorganic nanostructures}

Over the last decade, a few research groups resorted to combinatorial libraries of peptides displayed on $\mathrm{Ff}$ phage to vastly extend the types of inorganic materials that can be templated by viruses, including bacteriophages. By screening phage or cell surface display libraries, peptides that bind metals ( $\mathrm{Au}, \mathrm{Pt}, \mathrm{Pd}, \mathrm{Ag}$ ) semiconductor materials (GaAs, ZnS, CdS), paramagnetic materials (FePt, CoPt), electrode materials (e.g. $\mathrm{Co}_{3} \mathrm{O}_{4}, \mathrm{FePO}_{4}$; (Lee et al., 2009), catalysts (Neltner et al., 2010), $\mathrm{SiO}_{2}$, Zeolites, $\mathrm{CaCO}_{3}$, carbon nanotubes and many others have been isolated (reviewed in Flynn et al., 2003; Kriplani and Kay, 2005; Petrenko, 2008; Sarikaya et al., 2003). Filamentous phage not only allowed library screening to isolate inorganic material-binding peptides, but also served as a template for assembly of the nanometer scale structures (Mao et al., 2004).

Organic-inorganic liquid crystal nanostructures

The tendency of $\mathrm{Ff}$ phage to align and form liquid crystalline sheets has been exploited to utilize them as building blocks in assembly of three-dimensional lattices and films. In this application, the $\mathrm{Ff}$ particles displaying peptides that bind inorganic molecules at the plll end of the virion were highly concentrated and exposed to a magnetic field, which orients the particles due to the diamagnetic properties of pVIII major coat protein subunits. This results in formation of liquid crystalline layers of aligned viral filaments interspersed with the inorganic layers composed of the nanocrystals nucleated at the peptides displayed at the tips. When dried, these liquid crystal structures form a very stable film in which phage retain their infectivity for up to seven months (Lee et al., 2002).

The liquid crystalline nature of $\mathrm{Ff}$ can be exploited for forming fibers by wet spinning or electrospinning. Wet spinning is achieved by extruding $\mathrm{Ff}$ liquid crystals mixed with soluble polymer polyvinyl pyrolidone (PVP) through a capillary tube of $20 \mu \mathrm{m}$ into a glutaraldehyde solution, which cross-links the PVP and Ff fibers. Depending on the peptides displayed on $\mathrm{Ff}$, these fibers can be used for biomedical and tissue engineering or as templates for synthesis of electronic or optical materials. Moreover, Ff fibers produced by electrospinning can be used for nanofabrication or nanolithography (Lee and Belcher, 2004).

\section{Nanowires and nanorings}

High-density displayed nanocrystal-nucleating peptides along the filament of $\mathrm{Ff}$ have been used both as nucleators and templates for nanotube assembly. For example, exposure of phage displaying ZnS-nanocrystal-nucleating peptides to the $\mathrm{ZnS}$ solution at $0^{\circ} \mathrm{C}$ resulted in formation of a tube of nanocrystals wrapping the filament completely. Fast Fourier transformation showed that most of the nanocrystals assumed the same orientation relative to the filament (Mao et al., 2003). Furthermore, combination of two peptide specificities, for ZnS and CdS, nucleating the crystals along the filament, formed nanowires composed of both semiconductors (Mao et al., 2004).

Nanowires composed of virus and inorganic crystal can be transformed into inorganic nanowires by annealing, essentially heating to $350^{\circ} \mathrm{C}$ to eliminate the organic component, most importantly the nucleating peptides which prevent nanocrystals from fusing into a single-crystal nanowire. The resulting nanowires were 475-650 nm long,
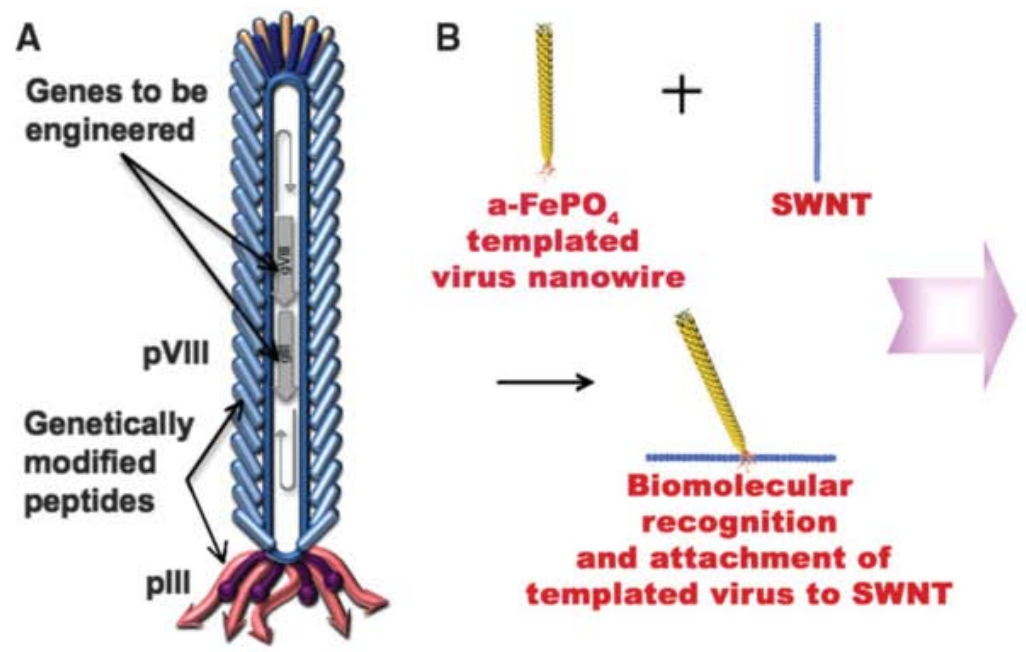

\section{High Power Lithium Ion Battery Cathode}

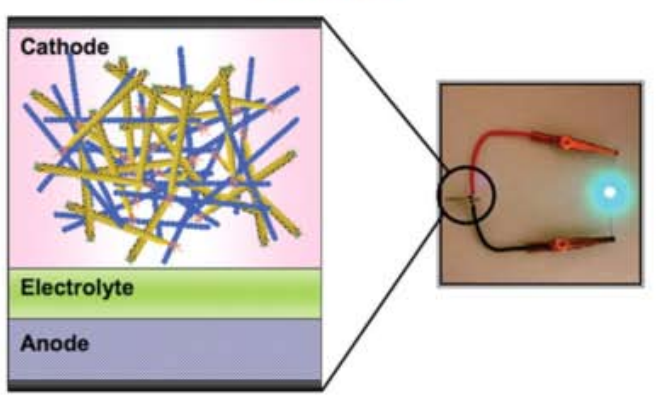

and attachment of templated virus to SWNT

Figure 7. Phage-templated electrode. A. Aschematic presentation of the multifunctional M13 virus with genetically engineered proteins. The $\mathrm{pVIII}$ is modified to serve as a template for a-FePO $\mathrm{Frowth}_{4}$ plll is engineered to have a binding affinity for SWNTs. B. A schematic diagram for fabricating genetically engineered high-power lithium-ion battery cathodes using multifunctional viruses (pVIII-pIII system) and a photograph of the battery used to power a green LED. The biomolecular recognition and attachment to conducting SWNT networks make efficient electrical nanoscale wiring to the active nanomaterials, enabling high power performance. These hybrid materials were assembled as a positive electrode in a lithium-ion battery using lithium metal foil as a negative electrode to power a green LED. Active cathode materials loading was $3.21 \mathrm{mg} / \mathrm{cm}^{2}$. The $2016 \mathrm{Coin}$ Cell used, which is $2 \mathrm{~cm}$ in diameter and $1.6 \mathrm{~mm}$ thick (From Lee et al., 2009, reprinted with permission from AAAS). 
with the diameter of $20 \mathrm{~nm}$, retaining the same crystal orientation as prior to annealing (Mao et al., 2003). The same method was applied to the assembly of ferromagnetic CoPt and FePt monocrystalline nanowires, with potential application in ultrahigh-density recording media (Mao et al., 2004; Reiss et al., 2004).

Not only wires, but more complex shapes can be produced by adding different functionalities to the ends of the Ff filaments. To form filamentous phage rings, a phage that carried ligands for a different binding specificity at each end was constructed: a poly-histidine peptide that binds nickel ions was displayed at the $\mathrm{pVII} / \mathrm{plX}$ end of the phage, and a streptavidin-binding peptide was displayed at the opposite, plll end of the filament; an adapter molecule with two binding functions, Ni-NTA and avidin, was used to join the filament ends (Nam et al., 2004).

In $2009 \mathrm{Ff}$ phage had its debut in gadget-making (Lee et al., 2009). In this technological feat, a phage displaying peptide EEEE was displayed on pVIII, allowing assembly of an anhydrous $\mathrm{FePO}_{4}$ nanowire along the filament, while peptide DMPRTTMSPPPR that binds single wall carbon nanotubes was displayed on plll (on one of the filament ends). Assembling $\mathrm{FePO}_{4}$ nanowires on a network made of Ff filaments and single wall nanotube hybrid nanostructures resulted in a high power lithium ion battery (Figure 7).

\section{Concluding remarks}

Filamentous phage have an enormous impact on many aspects of biology, pathogenesis and physiology of their host bacteria. Many questions remain unanswered, from those that refer to all filamentous phage, such as the structure of the virion caps, mechanisms of infection and assembly and the mechanism and structure of the assembly machinery, to the questions concerning lysogenic phage, specifically their replication and the nature of "virulent" or "superinfectious" phage. Future research into the surprising variety of cooperative arrangements between filamentous phage and their hosts should help elucidate aspects of bacterial adaptation to their environment.

While phage display as a combinatorial method is now a gold standard for finding antibodies and peptides of a desired specificity, its role in nanotechnology is rapidly expanding; discoveries to come will be limited only by the imagination of researchers.

\section{Acknowledgements}

This work was supported by the Royal Society of New Zealand Marsden Council Grant MAU210, Massey University Research Fund, Palmerston North Medical Research Fund, Lottery Health Board and Grant 280289 and New Zealand Foundation for Research and Technology contract C03X0701. N.J.B was supported by a Massey University Doctoral Scholarship and a Marsden Council Grant MAU210. J.S. was supported by a Massey University MSc scholarship and D.G. by a Bright Future Enterprise PhD Scholarship.

We are indebted to Peter Model and anonymous reviewers for critically reading and improving the manuscript. James Conway and Dalaver $\mathrm{H}$. Anjum are acknowledged for providing the unpublished electron micrograph of microphage. We are grateful to "Science" for permission to use published materials.

\section{References}

Antonara, S., Chafel, R.M., LaFrance, M., and Coburn, J. (2007). Borrelia burgdorferi adhesins identified using in vivo phage display. Mol Microbiol 66, 262-276.

Arap, W., Pasqualini, R., and Ruoslahti, E. (1998). Cancer treatment by targeted drug delivery to tumor vasculature in a mouse model. Science 279, 377-380.

Asano, S., Higashitani, A., and Horiuchi, K. (1999). Filamentous phage replication initiator protein gpll forms a covalent complex with the $5^{\prime}$ end of the nick it introduced. Nucleic Acids Res 27, 1882-1889.

Ausmees, N., Jacobsson, K., and Lindberg, M. (2001). A unipolarly located, cell-surface-associated agglutinin, RapA, belongs to a family of Rhizobium-adhering proteins (Rap) in Rhizobium leguminosarum bv. trifolii. Microbiology 147, 549-559.

Baca, M., Scanlan, T., Stephenson, R., and Wells, J. (1997). Phage display of a catalytic antibody to optimize affinity for transition-state analog binding. Proc Natl Acad Sci U S A 94, 10063-10068.

Barbas III, C.F., Burton, D.R., Scott, J.K., and Silverman, G.J. (2001). Phage display: a laboratory manual (Cold Spring Harbor, New York, Cold Spring Harbor Laboratory Press).

Barbas III, C.F., Kang, A.S., Lerner, R.A., and Benkovic, S.J. (1991). Assembly of combinatorial antibody libraries on phage surfaces: the gene III site. Proc Natl Acad Sci USA 88, 7978-7982.

Bardwell, J.C.A., McGovern, K., and Beckwith, J. (1991). Identification of a protein required for disulfide bond formation in vivo. Cell 67, 581-589.

Bayan, N., Guilvout, I., and Pugsley, A.P. (2006). Secretins take shape. Mol Microbiol 60, 1-4.

Bennett, N.J., Gagic, D., Sutherland-Smith, A.J., and Rakonjac, J. (2011). A specific sequence in the $C$ domain of plll is required for entry, but dispensable for release of Ff filamentous bacteriophage. Submitted.

Bennett, N.J., and Rakonjac, J. (2006). Unlocking of the filamentous bacteriophage virion during infection is mediated by the $\mathrm{C}$ domain of plll. J Mol Biol 356, 266273.

Bille, E., Ure, R., Gray, S.J., Kaczmarski, E.B., McCarthy, N.D., Nassif, X., Maiden, M.C., and Tinsley, C.R. (2008). Association of a bacteriophage with meningococcal disease in young adults. PLoS ONE 3, e3885.

Bille, E., Zahar, J.R., Perrin, A., Morelle, S., Kriz, P., Jolley, K.A., Maiden, M.C., Dervin, C., Nassif, X., and Tinsley, C.R. (2005). A chromosomally integrated bacteriophage in invasive meningococci. The Journal of experimental medicine 201, 1905-1913.

Block, A., Li, G., Fu, Z.Q., and Alfano, J.R. (2008). Phytopathogen type III effector weaponry and their plant targets. Current opinion in plant biology 11, 396-403.

Blond-Elguindi, S., Cwirla, S.E., Dower, W.J., Lipshutz, R.J., Sprang, S.R., Sambrook, J.F., and Gething, M.J. (1993). Affinity panning of a library of peptides displayed on bacteriophages reveals the binding specificity of BiP. Cell 75, 717-728.

Boeke, J.D., and Model, P. (1982). A prokaryotic membrane anchor sequence: carboxyl terminus of bacteriophage $\mathrm{f1}$ gene III protein retains it in the membrane. Proc Natl Acad Sci U S A 79, 5200-5204. 
Boeke, J.D., Model, P., and Zinder, N.D. (1982). Effects of bacteriophage f1 gene III protein on the host cell membrane. Mol Gen Genet 186, 185-192.

Bradbury, A.R., and Marks, J.D. (2004). Antibodies from phage antibody libraries. J Immunol Methods 290, 2949.

Brissette, J.L., Russel, M., Weiner, L., and Model, P. (1990). Phage shock protein, a stress protein of Escherichia coli. Proc Natl Acad Sci U S A 87, 862-866.

Burg, M., Ravey, E.P., Gonzales, M., Amburn, E., Faix, P.H., Baird, A., and Larocca, D. (2004). Selection of internalizing ligand-display phage using rolling circle amplification for phage recovery. DNA Cell Biol 23, 457-462.

Campos, J., Martinez, E., Marrero, K., Silva, Y., Rodriguez, B.L., Suzarte, E., Ledon, T., and Fando, R. (2003a). Novel type of specialized transduction for CTX $\phi$ or its satellite phage RS1 mediated by filamentous phage VGJ $\phi$ in Vibrio cholerae. J Bacteriol 185, 7231-7240.

Campos, J., Martinez, E., Suzarte, E., Rodriguez, B.L., Marrero, K., Silva, Y., Ledon, T., del Sol, R., and Fando, R. (2003b). VGJ $\phi$, a novel filamentous phage of Vibrio cholerae, integrates into the same chromosomal site as CTXф. J Bacteriol 185, 5685-5696.

Cascales, E., Buchanan, S.K., Duche, D., Kleanthous, C., Lloubes, R., Postle, K., Riley, M., Slatin, S., and Cavard, D. (2007). Colicin biology. Microbiol Mol Biol Rev 71, 158229.

Caspar, D.L.D., and Makowski, L. (1981). The symmetries of filamentous phage particles. J Mol Biol 145, 611-617.

Chamberlain, B.K., and Webster, R.E. (1978). Effect of membrane-associated $\mathrm{f} 1$ bacteriophage coat protein upon the activity of Escherichia coli phosphatidylserine synthetase. J Bacteriol 135, 883-887.

Chames, P., Willemsen, R.A., Rojas, G., Dieckmann, D., Rem, L., Schuler, G., Bolhuis, R.L., and Hoogenboom, H.R. (2002). TCR-like human antibodies expressed on human CTLs mediate antibody affinity-dependent cytolytic activity. J Immunol 169, 1110-1118.

Chami, M., Guilvout, I., Gregorini, M., Remigy, H.W., Muller, S.A., Valerio, M., Engel, A., Pugsley, A.P., and Bayan, N. (2005). Structural insights into the secretin PulD and its trypsin-resistant core. J Biol Chem 280, 37732-37741.

Chasteen, L., Ayriss, J., Pavlik, P., and Bradbury, A.R. (2006). Eliminating helper phage from phage display. Nucleic Acids Res 34, e145.

Cheadle, C., Ivashchenko, Y., South, V., Searfoss, G.H., French, S., Howk, R., Ricca, G.A., and Jaye, M. (1994). Identification of a Src SH3 domain binding motif by screening a random phage display library. J Biol Chem 269, 24034-24039.

Chen, L., Zurita, A.J., Ardelt, P.U., Giordano, R.J., Arap, W., and Pasqualini, R. (2004). Design and validation of a bifunctional ligand display system for receptor targeting. Chem Biol 11, 1081-1091.

Childers, B.M., and Klose, K.E. (2007). Regulation of virulence in Vibrio cholerae: the ToxR regulon. Future Microbiol 2, 335-344.

Choe, S., Bennett, M.J., Fujii, G., Curmi, P.M., Kantardjieff, K.A., Collier, R.J., and Eisenberg, D. (1992). The crystal structure of diphtheria toxin. Nature 357, 216-222.

Chopin, M.C., Rouault, A., Ehrlich, S.D., and Gautier, M. (2002). Filamentous phage active on the gram-positive bacterium Propionibacterium freudenreichii. J Bacteriol 184, 2030-2033.

Chouikha, I., Charrier, L., Filali, S., Derbise, A., and Carniel, E. (2010). Insights into the infective properties of Ypf $\phi$, the Yersinia pestis filamentous phage. Virology 407, 43-52.

Cicchini, C., Ansuini, H., Amicone, L., Alonzi, T., Nicosia, A., Cortese, R., Tripodi, M., and Luzzago, A. (2002). Searching for DNA-protein interactions by lambda phage display. J Mol Biol 322, 697-706.

Clackson, T., Hoogenboom, H.R., Griffiths, A.D., and Winter, G. (1991). Making antibody fragments using phage display libraries. Nature 352, 624-628.

Clackson, T., and Lowman, H.B. (2004). Practical approach to phage display (New York, Oxford University Press, Inc.).

Clarke, M., Maddera, L., Harris, R.L., and Silverman, P.M. (2008). F-pili dynamics by live-cell imaging. Proc Natl Acad Sci U S A 105, 17978-17981.

Clausen, M., Koomey, M., and Maier, B. (2009). Dynamics of type IV pili is controlled by switching between multiple states. Biophys J 96, 1169-1177.

Click, E.M., and Webster, R.E. (1997). Filamentous phage infection: required interactions with the TolA protein. $\mathrm{J}$ Bacteriol 179, 6464-6471.

Click, E.M., and Webster, R.E. (1998). The TolQRA proteins are required for membrane insertion of the major capsid protein of the filamentous phage $\mathrm{f} 1$ during infection. $J$ Bacteriol 180, 1723-1728.

Coburn, B., Sekirov, I., and Finlay, B.B. (2007). Type III secretion systems and disease. Clinical microbiology reviews $20,535-549$.

Craig, L., and Li, J. (2008). Type IV pili: paradoxes in form and function. Curr Opin Struct Biol 18, 267-277.

Crameri, R., and Blaser, K. (1996). Cloning Aspergillus fumigatus allergens by the pJuFo filamentous phage display system. Int Arch Allergy Immunol 110, 41-45.

Crameri, R., Jaussi, R., Menz, G., and Blaser, K. (1994). Display of expression products of cDNA libraries on phage surfaces. A versatile screening system for selective isolation of genes by specific gene-product/ligand interaction. Eur J Biochem 226, 53-58.

Cwirla, S.E., Peters, E.A., Barrett, R.W., and Dower, W.J. (1990). Peptides on phage: a vast library of peptides for identifying ligands. Proc Natl Acad Sci U S A 87, 63786382.

Daefler, S., Russel, M., and Model, P. (1997). Module swaps between related translocator proteins $\operatorname{pIV}(\mathrm{f} 1), \operatorname{pIV}(\mathrm{IKe})$ and PuID: Identification of a specificity domain. Journal of Molecular Biology 266, 978-992.

Dai, H., Tsay, S.H., Kuo, T.T., Lin, Y.H., and Wu, W.C. (1987). Neolysogenization of Xanthomonas campestris pv. citri infected with filamentous phage Cf16. Virology 156, 313-320.

Danner, S., and Belasco, J.G. (2001). T7 phage display: a novel genetic selection system for cloning RNA-binding proteins from cDNA libraries. Proc Natl Acad Sci U S A 98, 12954-12959.

Darwin, A.J. (2005). Genome-wide screens to identify genes of human pathogenic Yersinia species that are expressed during host infection. Curr Issues Mol Biol 7.

Darwin, A.J., and Miller, V.L. (1999). Identification of Yersinia enterocolitica genes affecting survival in an animal host 
using signature-tagged transposon mutagenesis. Mol Microbiol 32, 51-62.

Davis, B.M., Kimsey, H.H., Kane, A.V., and Waldor, M.K. (2002). A satellite phage-encoded antirepressor induces repressor aggregation and cholera toxin gene transfer. EMBO J 21, 4240-4249.

Davis, B.M., Lawson, E.H., Sandkvist, M., Ali, A., Sozhamannan, S., and Waldor, M.K. (2000). Convergence of the secretory pathways for cholera toxin and the filamentous phage, CTX $\phi$. Science 288, 333-335.

Davis, B.M., and Waldor, M.K. (2000). CTX $\phi$ contains a hybrid genome derived from tandemly integrated elements. Proc Natl Acad Sci U S A 97, 8572-8577.

Davis, N.G., Boeke, J.D., and Model, P. (1985). Fine structure of a membrane anchor domain. J Mol Biol 181, 111-121.

Davis, N.G., and Model, P. (1985). An artificial anchor domain: hydrophobicity suffices to stop transfer. Cell 41 , 607-614.

Day, L.A., Marzec, C.J., Reisberg, S.A., and Casadevall, A. (1988). DNA packing in filamentous bacteriophages Ann Rev Biophys Biophys Chem 17, 509-539.

de Haard, H.J., van Neer, N., Reurs, A., Hufton, S.E., Roovers, R.C., Henderikx, P., de Bruine, A.P., Arends, J.W., and Hoogenboom, H.R. (1999). A large nonimmunized human $F a b$ fragment phage library that permits rapid isolation and kinetic analysis of high affinity antibodies. J Biol Chem 274, 18218-18230.

de Wildt, R.M., Tomlinson, I.M., Ong, J.L., and Holliger, P. (2002). Isolation of receptor-ligand pairs by capture of long-lived multivalent interaction complexes. Proc Natl Acad Sci U S A 99, 8530-8535.

DeLano, W.L. (2006). The PyMOL Molecular Graphics System (DeLano Scientific, San Carlos, CA, USA).

Deng, L.W., Malik, P., and Perham, R.N. (1999). Interaction of the globular domains of plll protein of filamentous bacteriophage fd with the F-pilus of Escherichia coli. Virology 253, 271-277.

Deng, L.W., and Perham, R.N. (2002). Delineating the site of interaction on the plll protein of filamentous bacteriophage fd with the F-pilus of Escherichia coli. J Mol Biol 319, 603614.

Devlin, J.J., Panganiban, L.C., and Devlin, P.E. (1990). Random peptide libraries: a source of specific protein binding molecules. Science 249, 404-406.

Di Niro, R., Sulic, A.M., Mignone, F., D'Angelo, S., Bordoni, R., lacono, M., Marzari, R., Gaiotto, T., Lavric, M., Bradbury, A.R., Biancone, L., Zevin-Sonkin, D., De Bellis, G., Santoro, C., et al. (2010). Rapid interactome profiling by massive sequencing. Nucleic Acids Res 38, e110.

Dias-Neto, E., Nunes, D.N., Giordano, R.J., Sun, J., Botz, G.H., Yang, K., Setubal, J.C., Pasqualini, R., and Arap, W. (2009). Next-generation phage display: integrating and comparing available molecular tools to enable costeffective high-throughput analysis. PLoS ONE 4, e8338.

Eckert, B., Martin, A., Balbach, J., and Schmid, F.X. (2007). Prolyl Isomerization as a Molecular Timer in Phage Infection. Nature Structural and Molecular Biology 12, 619-623.

Endemann, H., Bross, P., and Rasched, I. (1992). The adsorption protein of phage IKe. Localization by deletion mutagenesis of domains involved in infectivity. Mol Microbiol 6, 471-478.
Endemann, H., and Model, P. (1995). Location of filamentous phage minor coat proteins in phage and in infected cells. $\mathrm{J}$ Mol Biol 250, 496-506.

Felici, F., Luzzago, A., Folgori, A., and Cortese, R. (1993). Mimicking of discontinuous epitopes by phage-displayed peptides, II. Selection of clones recognized by a protective monoclonal antibody against the Bordetella pertussis toxin from phage peptide libraries. Gene 128, 21-27.

Feng, J.-n. (2000). Studies of the assembly/export proteins and energy requirements for filamentous phage assembly (The Rockefeller University).

Feng, J.N., Model, P., and Russel, M. (1999). A transenvelope protein complex needed for filamentous phage assembly and export. Mol Microbiol 34, 745-755.

Feng, J.N., Russel, M., and Model, P. (1997). A permeabilized cell system that assembles filamentous bacteriophage. Proc Natl Acad Sci USA 94, 4068-4073.

Fields, S., and Song, O.-k. (1989). A novel genetic system to detect protein-protein interactions. Nature 340, 245-246.

Flynn, C., Lee, S., Peelle, B., and Belcher, A. (2003). Viruses as vehicles for growth, organization and assembly of materials. ACTA MATER 51, 5867-5880.

Forrer, P., Jung, S., and Pluckthun, A. (1999). Beyond binding: using phage display to select for structure, folding and enzymatic activity in proteins. Curr Opin Struct Biol 9, 514-520.

Frye, S.A., Assalkhou, R., Collins, R.F., Ford, R.C., Petersson, C., Derrick, J.P., and Tonjum, T. (2006). Topology of the outer-membrane secretin PilQ from Neisseria meningitidis. Microbiology 152, 3751-3764.

Fuh, G., and Sidhu, S.S. (2000). Efficient phage display of polypeptides fused to the carboxy-terminus of the M13 gene-3 minor coat protein. FEBS Lett 480, 231-234.

Fujii, I., Fukuyama, S., Iwabuchi, Y., and Tanimura, R. (1998). Evolving catalytic antibodies in a phage-displayed combinatorial library. Nat Biotechnol 16, 463-467.

Galan, J.E., and Collmer, A. (1999). Type III secretion machines: bacterial devices for protein delivery into host cells. Science 284, 1322-1328.

Gao, C., Lin, C.H., Lo, C.H., Mao, S., Wirsching, P., Lerner, R.A., and Janda, K.D. (1997). Making chemistry selectable by linking it to infectivity. Proc Natl Acad Sci U S A 94, 11777-11782.

Gao, C., Mao, S., Kaufmann, G., Wirsching, P., Lerner, R.A., and Janda, K.D. (2002). A method for the generation of combinatorial antibody libraries using pIX phage display. Proc Natl Acad Sci U S A 99, 12612-12616.

Gao, C., Mao, S., Lo, C.H., Wirsching, P., Lerner, R.A., and Janda, K.D. (1999). Making artificial antibodies: a format for phage display of combinatorial heterodimeric arrays. Proc Natl Acad Sci U S A 96, 6025-6030.

Gerding, M.A., Ogata, Y., Pecora, N.D., Niki, H., and de Boer, P.A. (2007). The trans-envelope Tol-Pal complex is part of the cell division machinery and required for proper outer-membrane invagination during cell constriction in $E$. coli. Mol Microbiol 63, 1008-1025.

Goldbourt, A., Day, L.A., and McDermott, A.E. (2010). Intersubunit hydrophobic interactions in Pf1 filamentous phage. J Biol Chem 285, 37051-37059.

Goldbourt, A., Gross, B.J., Day, L.A., and McDermott, A.E. (2007). Filamentous phage studied by magic-angle spinning NMR: resonance assignment and secondary 
structure of the coat protein in Pf1. J Am Chem Soc 129, 2338-2344.

Gonzalez, M.D., Lichtensteiger, C.A., Caughlan, R., and Vimr, E.R. (2002). Conserved filamentous prophage in Escherichia coli $018: \mathrm{K} 1: \mathrm{H} 7$ and Yersinia pestis biovar orientalis. J Bacteriol 184, 6050-6055.

Grant, R., Lin, T., Webster, R., and Konigsberg, W. (1980). Structure of filamentous bacteriophage: isolation, characterization, and localization of the minor coat proteins and orientation of the DNA. In Bacteriophage assembly, M. DuBow, ed. (New York, Alan. R. Liss, Inc.), pp. 413-428.

Greenstein, D., Zinder, N.D., and Horiuchi, K. (1988). Integration host factor interacts with the DNA replicatin enhancer of filamentous phage f1. Proc Natl Acad 85, 6262-6266.

Griffiths, A.D., Malmqvist, M., Marks, J.D., Bye, J.M., Embleton, M.J., McCafferty, J., Baier, M., Holliger, K.P., Gorick, B.D., Hughes-Jones, N.C., and et al. (1993). Human anti-self antibodies with high specificity from phage display libraries. Embo J 12, 725-734.

Gueguen, E., Savitzky, D.C., and Darwin, A.J. (2009). Analysis of the Yersinia enterocolitica PspBC proteins defines functional domains, essential amino acids and new roles within the phage-shock-protein response. Mol Microbiol 74, 619-633.

Haigh, N.G., and Webster, R.E. (1999). The pl and pXI assembly proteins serve separate and essential roles in filamentous phage assembly. J Mol Biol 293, 1017-1027.

Hansson, L.O., Widersten, M., and Mannervik, B. (1997). Mechanism-based phage display selection of active-site mutants of human glutathione transferase A1-1 catalyzing SNAr reactions. Biochemistry 36, 11252-11260.

Hassan, F., Kamruzzaman, M., Mekalanos, J.J., and Faruque, S.M. (2010). Satellite phage TLC $\phi$ enables toxigenic conversion by CTX phage through dif site alteration. Nature 467, 982-985.

Heilpern, A.J., and Waldor, M.K. (2000). CTX $\phi$ infection of Vibrio cholerae requires the tolQRA gene products. J Bacteriol 182, 1739-1747.

Heilpern, A.J., and Waldor, M.K. (2003). plIICTX, a predicted CTX $\phi$ minor coat protein, can expand the host range of coliphage fd to include Vibrio cholerae. J Bacteriol 185, 1037-1044.

Hemminga, M.A., Vos, W.L., Nazarov, P.V., Koehorst, R.B., Wolfs, C.J., Spruijt, R.B., and Stopar, D. (2010). Viruses: incredible nanomachines. New advances with filamentous phages. Eur Biophys J 39, 541-550.

Higashitani, A., Higashitani, N., and Horiuchi, K. (1997). Minus-strand origin of filamentous phage versus transcriptional promoters in recognition of RNA polymerase. Proc Natl Acad Sci U S A 94, 2909-2914.

Hodgkinson, J.L., Horsley, A., Stabat, D., Simon, M., Johnson, S., da Fonseca, P.C., Morris, E.P., Wall, J.S., Lea, S.M., and Blocker, A.J. (2009). Three-dimensional reconstruction of the Shigella T3SS transmembrane regions reveals 12-fold symmetry and novel features throughout. Nat Struct Mol Biol 16, 477-485.

Hoffman-Berling, H., Durwald, H., and Beulke, I. (1963). Ein fadiger DNS-phage $(\mathrm{fd})$ und ein spharischer RNS-phage (fr) wirtsspezifisch fur mannliche Stamme von E. coli, III. Biologisches verhalten von fd und fr. Fadiger DNS-Phage (fd) und Spharischer RNS-Phage (fr) III, 893-898.
Hofschneider, P.H. (1963). Untersuchungen über "kleine" E. coli K12 Bakteriophagen. Z Naturforschung 18B, 203210.

Holland, S.J., Sanz, C., and Perham, R.N. (2006). Identification and specificity of pilus adsorption proteins of filamentous bacteriophages infecting Pseudomonas aeruginosa. Virology 345, 540-548.

Holliger, P., Riechmann, L., and Williams, R.L. (1999). Crystal structure of the two N-terminal domains of g3p from filamentous phage fd at $1.9 \mathrm{~A}$ : evidence for conformational lability. J Mol Biol 288, 649-657.

Horabin, J.I., and Webster, R.E. (1988). An amino acid sequence which directs membrane insertion causes loss of membrane potential. J Biol Chem 263, 11575-11583.

Horiuchi, K. (1997). Initiation mechanisms in replication of filamentous phage DNA. Genes Cells 2, 425-432.

Huang, Y., Chiang, C.Y., Lee, S.K., Gao, Y., Hu, E.L., De Yoreo, J., and Belcher, A.M. (2005). Programmable assembly of nanoarchitectures using genetically engineered viruses. Nano letters 5, 1429-1434.

Huber, K.E., and Waldor, M.K. (2002). Filamentous phage integration requires the host recombinases XerC and XerD. Nature 417, 656-659.

lannolo, G., Minenkova, O., Petruzzelli, R., and Cesareni, G. (1995). Modifying filamentous phage capsid: limits in the size of the major capsid protein. J Mol Biol 248, 835844.

ICTVdB (2008). ICTVdB Index of Viruses.

International Committee on Taxonomy of Viruses. (2005). Virus taxonomy. Eighth report of the International Committee on Taxonomy of Viruses (London, Elsevier/ Academic Press).

Janda, K.D., Lo, L.C., Lo, C.H., Sim, M.M., Wang, R., Wong, C.H., and Lerner, R.A. (1997). Chemical selection for catalysis in combinatorial antibody libraries. Science 275 , 945-948.

Jankovic, D., Collett, M.A., Lubbers, M.W., and Rakonjac, J. (2007). Direct selection and phage display of a Grampositive secretome. Genome Biol 8, R266.

Jespers, L.S., De Keyser, A., and Stanssens, P.E. (1996). LambdaZLG6: a phage lambda vector for high-efficiency cloning and surface expression of cDNA libraries on filamentous phage. Gene 173, 179-181.

Johnson, T.L., Abendroth, J., Hol, W.G., and Sandkvist, M. (2006). Type II secretion: from structure to function. FEMS Microbiol Lett 255, 175-186.

Joly, N., Engl, C., Jovanovic, G., Huvet, M., Toni, T., Sheng, X., Stumpf, M.P., and Buck, M. (2010). Managing membrane stress: the phage shock protein (Psp) response, from molecular mechanisms to physiology. FEMS Microbiol Rev 34, 797-827.

Jouravleva, E.A., McDonald, G.A., Marsh, J.W., Taylor, R.K., Boesman-Finkelstein, M., and Finkelstein, R.A. (1998). The Vibrio cholerae mannose-sensitive hemagglutinin is the receptor for a filamentous bacteriophage from $V$. cholerae 0139. Infect Immun 66, 2535-2539.

Jovanovic, G., Engl, C., and Buck, M. (2009). Physical, functional and conditional interactions between ArcAB and phage shock proteins upon secretin-induced stress in Escherichia coli. Mol Microbiol 74, 16-28.

Jovanovic, G., Engl, C., Mayhew, A.J., Burrows, P.C., and Buck, M. (2010). Properties of the phage-shock-protein (Psp) regulatory complex that govern signal transduction 
and induction of the Psp response in Escherichia coli. Microbiology 156, 2920-2932.

Jovanovic, G., Lloyd, L.J., Stumpf, M.P., Mayhew, A.J., and Buck, M. (2006). Induction and function of the phage shock protein extracytoplasmic stress response in Escherichia coli. J Biol Chem 281, 21147-21161.

Kang, A.S., Barbas III, C.F., Janda, K.D., Lerner, R.A., and Benkovic, S.J. (1991). Linkage of recognition and replication functions by assembling combinatorial antibody Fab libraries along phage surfaces. Proc Natl Acad Sci USA 88, 4363-4366.

Khatoon, H., lyer, R.V., and lyer, V.N. (1972). A new filamentous bacteriophage with sex-factor specificity. Virology 48, 145-155.

Kim, A.Y., and Blaschek, H.P. (1991). Isolation and characterization of a filamentous viruslike particle from Clostridium acetobutylicum NCIB 6444. J Bacteriol 173, 530-535.

Kim, M.H., Hines, J.C., and Ray, D.S. (1981). Viable deletions of the M13 complementary strand origin. Proc Natl Acad Sci 78, 6784-6788.

Kimsey, H.H., and Waldor, M.K. (2004). The CTX $\phi$ repressor RstR binds DNA cooperatively to form tetrameric repressor-operator complexes. J Biol Chem 279, 26402647.

Kimsey, H.H., and Waldor, M.K. (2009). Vibrio cholerae LexA coordinates CTX prophage gene expression. J Bacteriol 191, 6788-6795.

Koiwa, H., D'Urzo, M.P., Assfalg-Machleidt, I., Zhu-Salzman, K., Shade, R.E., An, H., Murdock, L.L., Machleidt, W., Bressan, R.A., and Hasegawa, P.M. (2001). Phage display selection of hairpin loop soyacystatin variants that mediate high affinity inhibition of a cysteine proteinase. Plant J 27, 383-391.

Kriplani, U., and Kay, B.K. (2005). Selecting peptides for use in nanoscale materials using phage-displayed combinatorial peptide libraries. Curr Opin Biotechnol 16, 470-475.

Krogh, A., Larsson, B., von Heijne, G., and Sonnhammer, E.L. (2001). Predicting transmembrane protein topology with a hidden Markov model: application to complete genomes. J Mol Biol 305, 567-580.

Kuo, T.T., Chiang, C.C., Chen, S.Y., Lin, J.H., and Kuo, J.L. (1994). A long lytic cycle in filamentous phage Cf1tv infecting Xanthomonas campestris pv. citri. Arch Virol 135, 253-264.

La Farina, M., Izzo, V., Duro, G., Barbieri, R., Assunta Costa, M., and Mutolo, V. (1987). Intragenomic recombination between homolouges regions of genes II and IV promotes formation of bacteriophage $\mathrm{f} 1$ miniphages. Nucl Acids Res 15, 7190.

Larocca, D., Jensen-Pergakes, K., Burg, M.A., and Baird, A. (2002). Gene transfer using targeted filamentous bacteriophage. Methods Mol Biol 185, 393-401.

Lawley, T.D., Klimke, W.A., Gubbins, M.J., and Frost, L.S. (2003). F factor conjugation is a true type IV secretion system. FEMS Microbiol Lett 224, 1-15.

Lee, S., and Belcher, A. (2004). Virus-based fabrication of micro- and nanofibers using electrospinning. Nano letters 4, 387-390.

Lee, S., Mao, C., Flynn, C., and Belcher, A. (2002). Ordering of quantum dots using genetically engineered viruses. Science 296, 892-895.
Lee, Y.J., Yi, H., Kim, W.J., Kang, K., Yun, D.S., Strano, M.S., Ceder, G., and Belcher, A.M. (2009). Fabricating genetically engineered high-power lithium-ion batteries using multiple virus genes. Science 324, 1051-1055.

Li, K., Chen, Y., Li, S.Q., Huong, G.N., Niu, Z.W., You, S.J., Mello, C.M., Lu, X.B., and Wang, Q.A. (2010). Chemical modification of M13 bacteriophage and Its application in cancer cell imaging. Bioconj Chemistry 21, 1369-1377.

Lin, N.T., Chang, R.Y., Lee, S.J., and Tseng, Y.H. (2001). Plasmids carrying cloned fragments of RF DNA from the filamentous phage $\phi \mathrm{Lf}$ can be integrated into the host chromosome via site-specific integration and homologous recombination. Mol Genet Genomics 266, 425-435.

Lindmark, H., Jacobsson, K., Frykberg, L., and Guss, B. (1996). Fibronectin-binding protein of Streptococcus equi subsp. zooepidemicus. Infect Immun 64, 3993-3999.

Liu, D.J., and Day, L.A. (1994). Pf1 virus structure: helical coat protein and DNA with paraxial phosphates. Science 265, 671-674.

Loeb, T. (1960). Isolation of a bacteriophage specific for the $\mathrm{F}^{+}$and $\mathrm{Hfr}$ mating types of Escherichia coli K-12. Science 131, 932-933.

Lopez, J., and Webster, R.E. (1983). Morphogenesis of filamentous bacteriophage $\mathrm{f} 1$ : orientation of extrusion and production of polyphage. Virology 127, 177-193.

Lorenz, S.H., Jakob, R.P., Weininger, U., Balbach, J., Dobbek, H., and Schmid, F.X. (2011). The filamentous phages fd and IF1 use different mechanisms to infect Escherichia coli. J Mol Biol 405, 989-1003.

Lowman, H.B., Bass, S.H., Simpson, N., and Wells, J.A. (1991). Selecting high-affinity binding proteins by monovalent phage display. Biochemistry 30, 1083210838.

Lubkowski, J., Hennecke, F., Pluckthun, A., and Wlodawer, A. (1998). The structural basis of phage display elucidated by the crystal structure of the $\mathrm{N}$-terminal domains of $\mathrm{g} 3 \mathrm{p}$. Nat Struct Biol 5, 140-147.

Lubkowski, J., Hennecke, F., Pluckthun, A., and Wlodawer, A. (1999). Filamentous phage infection: crystal structure of $g 3 p$ in complex with its coreceptor, the C-terminal domain of TolA. Structure Fold Des 15, 711-272.

Maier, B. (2005). Using laser tweezers to measure twitching motility in Neisseria. Current opinion in microbiology 8 , 344-349.

Mao, C., Flynn, C., Hayhurst, A., Sweeney, R., Qi, J., Georgiou, G., Iverson, B., and Belcher, A. (2003). Viral assembly of oriented quantum dot nanowires. Proc Natl Acad Sci U S A 100, 6946-6951.

Mao, C., Solis, D., Reiss, B., Kottmann, S., Sweeney, R., Hayhurst, A., Georgiou, G., Iverson, B., and Belcher, A. (2004). Virus-based toolkit for the directed synthesis of magnetic and semiconducting nanowires. Science 303, 213-217.

Marciano, D.K., Russel, M., and Simon, S.M. (1999). An aqueous channel for filamentous phage export. Science 284, 1516-1519.

Marciano, D.K., Russel, M., and Simon, S.M. (2001). Assembling filamentous phage occlude pIV channels. Proc Natl Acad Sci USA 98, 9359-9364.

Marks, J.D., Hoogenboom, H.R., Bonnert, T.P., McCafferty, J., Griffiths, A.D., and Winter, G. (1991). By-passing immunization. Human antibodies from $V$-gene libraries displayed on phage. J Mol Biol 222, 581-597. 
Marlovits, T.C., Kubori, T., Sukhan, A., Thomas, D.R., Galan, J.E., and Unger, V.M. (2004). Structural insights into the assembly of the type III secretion needle complex. Science 306, 1040-1042.

Marlovits, T.C., and Stebbins, C.E. (2010). Type III secretion systems shape up as they ship out. Current opinion in microbiology 13, 47-52.

Marvin, D., and Hoffmann-Berling, H. (1963). Physical and chemical properties of two new small bacteriophages. Nature 197, 517-518.

Marvin, D.A. (1998). Filamentous phage structure, infection and assembly. Curr Opin Struct Biol 8, 150-158.

Marvin, D.A., Welsh, L.C., Symmons, M.F., Scott, W.R., and Straus, S.K. (2006). Molecular structure of fd (f1, M13) filamentous bacteriophage refined with respect to X-ray fibre diffraction and solid-state NMR data supports specific models of phage assembly at the bacterial membrane. $\mathrm{J}$ Mol Biol 355, 294-309.

Marzari, R., Sblattero, D., Righi, M., and Bradbury, A. (1997). Extending filamentous phage host range by the grafting of a heterologous receptor binding domain. Gene 185, 27-33.

Maxson, M.E., and Darwin, A.J. (2006). PspB and PspC of Yersinia enterocolitica are dual function proteins: regulators and effectors of the phage-shock-protein response. Mol Microbiol 59, 1610-1623.

McCafferty, J., Griffiths, A.D., Winter, G., and Chiswell, D.J. (1990). Phage antibodies: filamentous phage displaying antibody variable domains. Nature $348,552-554$.

McCafferty, J., Jackson, R.H., and Chiswell, D.J. (1991). Phage-enzymes: expression and affinity chromatography of functional alkaline phosphatase on the surface of bacteriophage. Protein Eng 4, 955-961.

McLeod, S.M., Kimsey, H.H., Davis, B.M., and Waldor, M.K. (2005). CTX $\phi$ and Vibrio cholerae: exploring a newly recognized type of phage-host cell relationship. Mol Microbiol 57, 347-356.

Meyer, T.F., and Geider, K. (1982). Enzymatic synthesis of bacteriophage fd viral DNA. Nature 296, 828-832.

Meynell, G.G., and Lawn, A.M. (1968). Filamentous phages specific for the I sex factor. Nature 217, 1184-1186.

Michel, B., and Zinder, N.D. (1989). Translational repression in bacteriophage $\mathrm{f1}$ : characterization of the gene $\mathrm{V}$ protein target on the gene II mRNA. Proc Natl Acad Sci 86, 40024006.

Model, P., Jovanovic, G., and Dworkin, J. (1997). The Escherichia coli phage shock protein operon. Mol Microbiol 24, 255-261.

Mooij, M.J., Drenkard, E., Llamas, M.A., VandenbrouckeGrauls, C.M., Savelkoul, P.H., Ausubel, F.M., and Bitter, W. (2007). Characterization of the integrated filamentous phage Pf5 and its involvement in small-colony formation. Microbiology 153, 1790-1798.

Moraes, T.F., Spreter, T., and Strynadka, N.C. (2008). Piecing together the type III injectisome of bacterial pathogens. Curr Opin Struct Biol 18, 258-266.

Moyer, K.E., Kimsey, H.H., and Waldor, M.K. (2001). Evidence for a rolling-circle mechanism of phage DNA synthesis from both replicative and integrated forms of CTX $\phi$. Mol Microbiol 41, 311-323.

Nam, K., Peelle, B., Lee, S., and Belcher, A. (2004). Genetically driven assembly of nanorings based on the M13 virus. Nano letters 4, 23-27.
Nasu, H., lida, T., Sugahara, T., Yamaichi, Y., Park, K.S., Yokoyama, K., Makino, K., Shinagawa, H., and Honda, T. (2000). A filamentous phage associated with recent pandemic Vibrio parahaemolyticus O3:K6 strains. J Clin Microbiol 38, 2156-2161.

Neltner, B., Peddie, B., Xu, A., Doenlen, W., Durand, K., Yun, D.S., Speakman, S., Peterson, A., and Belcher, A. (2010). Production of hydrogen using nanocrystalline protein-templated catalysts on M13 phage. Acs Nano 4, 3227-3235.

Newman, J., Swinney, H.L., and Day, L.A. (1977). Hydrodynamic properties and structure of fd virus. J Mol Biol 116, 593-603.

Oh, M.Y., Joo, H.Y., Hur, B.U., Jeong, Y.H., and Cha, S.H. (2007). Enhancing phage display of antibody fragments using glll-amber suppression. Gene 386, 81-89.

Opalka, N., Beckmann, R., Boisset, N., Simon, M.N., Russel, M., and Darst, S.A. (2003). Structure of the filamentous phage pIV multimer by cryo-electron microscopy. J Mol Biol 325, 461-470.

Opella, S.J., Zeri, A.C., and Park, S.H. (2008). Structure, dynamics, and assembly of filamentous bacteriophages by nuclear magnetic resonance spectroscopy. Annu Rev Phys Chem 59, 635-657.

Papavoine, C.H., Christiaans, B.E., Folmer, R.H., Konings, R.N., and Hilbers, C.W. (1998). Solution structure of the M13 major coat protein in detergent micelles: a basis for a model of phage assembly involving specific residues. J Mol Biol 282, 401-419.

Park, S.H., Marassi, F.M., Black, D., and Opella, S.J. (2010). Structure and dynamics of the membrane-bound form of Pf1 coat protein: implications of structural rearrangement for virus assembly. Biophys J 99, 1465-1474.

Parmley, S.F., and Smith, G.P. (1988). Antibody-selectable filamentous fd phage vectors - affinity purification of target genes Gene 73, 305-318.

Pasqualini, R., and Ruoslahti, E. (1996). Organ targeting in vivo using phage display peptide libraries. Nature 380 , 364-366.

Pelicic, V. (2008). Type IV pili: e pluribus unum? Mol Microbiol 68, 827-837.

Perez-Rodriguez, R., Haitjema, C., Huang, Q., Nam, K.H., Bernardis, S., Ke, A., and Delisa, M.P. (2011). Envelope stress is a trigger of CRISPR RNA-mediated DNA silencing in Escherichia coli. Mol Microbiol 79, 584-599.

Petrenko, V. (2008). Evolution of phage display: from bioactive peptides to bioselective nanomaterials. Expert Opin Drug Deliv 5, 825-836.

Poul, M.A., Becerril, B., Nielsen, U.B., Morisson, P., and Marks, J.D. (2000). Selection of tumor-specific internalizing human antibodies from phage libraries. J Mol Biol 301, 1149-1161.

Pratt, D., Tzagoloff, H., and Erdahl, W.S. (1966). Conditional lethal mutants of the small filamentous coliphage M13. I. Isolation, complementation, cell killing, time of cistron action. Virology 30, 397-410.

Quinones, M., Kimsey, H.H., and Waldor, M.K. (2005). LexA cleavage is required for CTX prophage induction. Mol Cell 17, 291-300.

Rakonjac, J., Feng, J.N., and Model, P. (1999). Filamentous phage are released from the bacterial membrane by a twostep mechanism involving a short C-terminal fragment of plll. J Mol Biol 289, 1253-1265. 
Rakonjac, J., Jovanovic, G., and Model, P. (1997). Filamentous phage infection-mediated gene expression: construction and propagation of the glll deletion mutant helper phage R408d3. Gene 198, 99-103.

Rakonjac, J., and Model, P. (1998). The roles of plll in filamentous phage assembly. J Mol Biol 282, 25-41.

Rapoza, M.P., and Webster, R.E. (1995). The products of gene $\mathrm{I}$ and the overlapping in-frame gene $\mathrm{XI}$ are required for filamentous phage assembly. J Mol Biol 248, 627638.

Rebar, E.J., and Pabo, C.O. (1994). Zinc finger phage: affinity selection of fingers with new DNA-binding specificities. Science 263, 671-673.

Reichmann, L., and Holliger, P. (1997). The C-terminal domain of TolA is the coreceptor for filamentous phage infection of E. coli. Cell 90, 351-360.

Reichow, S.L., Korotkov, K.V., Hol, W.G., and Gonen, T. (2010). Structure of the cholera toxin secretion channel in its closed state. Nat Struct Mol Biol 17, 1226-1232.

Reiss, B., Mao, C., Solis, D., Ryan, K., Thomson, T., and Belcher, A. (2004). Biological routes to metal alloy ferromagnetic nanostructures. Nano letters 4, 11271132.

Rice, S.A., Tan, C.H., Mikkelsen, P.J., Kung, V., Woo, J., Tay, M., Hauser, A., McDougald, D., Webb, J.S., and Kjelleberg, S. (2009). The biofilm life cycle and virulence of Pseudomonas aeruginosa are dependent on a filamentous prophage. ISME J 3, 271-282.

Rieul, C., Cortay, J.C., Bleicher, F., and Cozzone, A.J. (1987). Effect of bacteriophage M13 infection on phosphorylation of DnaK protein and other Escherichia coli proteins. Eur J Biochem 168, 621-627.

Roberts, B.L., Markland, W., Ley, A.C., Kent, R.B., White, D.W., Guterman, S.K., and Ladner, R.C. (1992). Directed evolution of a protein: selection of potent neutrophil elastase inhibitors displayed on M13 fusion phage. Proc Natl Acad Sci U S A 89, 2429-2433.

Rodi, D.J., Makowski, L., and Kay, B.K. (2002). One from column $A$ and two from column $B$ : the benefits of phage display in molecular-recognition studies. Curr Opin Chem Biol 6, 92-96.

Rohrer, J., and Kuhn, A. (1990). The function of a leader peptide in translocating charged amino acyl residues across a membrane. Science 250, 1418-1421.

Russel, M. (1993). Protein-protein interactions during filamentous phage assembly. J Mol Biol 231, 689-697.

Russel, M. (1998). Macromolecular assembly and secretion across the bacterial cell envelope: type II protein secretion systems. J Mol Biol 279, 485-499.

Russel, M., and Model, P. (1982). Filamentous phage precoat is an integral membrane protein: analysis by a new method of membrane preparation. Cell 28, 177-184.

Russel, M., and Model, P. (1989). Genetic analysis of the filamentous bacteriophage packaging signal and of the proteins that interact with it. J Virol 63, 3284-3295.

Russel, M., and Model, P. (2006). Filamentous Phage. In The Bacteriophages (Second Edition), R.C. Calendar, ed. (New York, Oxford University Press, Inc.), pp. 146-160.

Russel, M., Whirlow, H., Sun, T.P., and Webster, R.E. (1988). Low-frequency infection of $\mathrm{F}^{-}$bacteria by transducing particles of filamentous bacteriophages $\mathrm{J}$ Bacteriol 170, 5312-5316.
Samuelson, J., Chen, M., Jiang, F., Möller, I., Wiedmann, M., Kuhn, A., Phillips, G., and Dalbey, R. (2000). YidC mediates membrane protein insertion in bacteria. Nature 406, 637-641.

Sandkvist, M. (2001). Type II secretion and pathogenesis. Infect Immun 69, 3523-3535.

Sarikaya, M., Tamerler, C., Jen, A., Schulten, K., and Baneyx, F. (2003). Molecular biomimetics: nanotechnology through biology. NAT MATER 2, 577-585.

Sblattero, D., and Bradbury, A. (2000). Exploiting recombination in single bacteria to make large phage antibody libraries. Nat Biotechnol 18, 75-80.

Schier, R., Bye, J., Apell, G., McCall, A., Adams, G.P., Malmqvist, M., Weiner, L.M., and Marks, J.D. (1996). Isolation of high-affinity monomeric human anti-c-erbB-2 single chain Fv using affinity-driven selection. J Mol Biol 255, 28-43.

Schier, R., Marks, J.D., Wolf, E.J., Apell, G., Wong, C., McCartney, J.E., Bookman, M.A., Huston, J.S., Houston, L.L., Weiner, L.M., and et al. (1995). In vitro and in vivo characterization of a human anti-c-erbB-2 single-chain Fv isolated from a filamentous phage antibody library. Immunotechnology 1, 73-81.

Schwartz, F.M., and Zinder, N. (1968). Morphological changes in Escherichia coli infected with the DNA bacteriophage f1. Virology 34, 352-355.

Scott, J.K., and Smith, G.P. (1990). Searching for peptide ligands with an epitope library. Science 249, 386-390.

Seo, J., Savitzky, D.C., Ford, E., and Darwin, A.J. (2007). Global analysis of tolerance to secretin-induced stress in Yersinia enterocolitica suggests that the phage-shockprotein system may be a remarkably self-contained stress response. Mol Microbiol 65, 714-727.

Serek, J., Bauer-Manz, G., Struhalla, G., van den Berg, L., Kiefer, D., Dalbey, R., and Kuhn, A. (2004). Escherichia coli YidC is a membrane insertase for Sec-independent proteins. Embo J 23, 294-301.

Smilowitz, H. (1974). Bacteriophage f1 infection: fate of the parental major coat protein. J Virol 13, 94-99.

Sobry, S., Havelange, A., Liners, F., and Van Cutsem, P. (2005). Immunolocalization of homogalacturonans in the apex of the long-day plant Sinapis alba at floral transition. The pectin content drops dramatically in the first hours of this transition. PHYSIOL PLANTARUM 123, 339-347.

Soumillion, P., Jespers, L., Bouchet, M., Marchand-Brynaert, J., Winter, G., and Fastrez, J. (1994). Selection of betalactamase on filamentous bacteriophage by catalytic activity. J Mol Biol 237, 415-422.

Spagnuolo, J., Opalka, N., Wen, W.X., Gagic, D., Chabaud, E., Bellini, P., Bennett, M.D., Norris, G.E., Darst, S.A., Russel, M., and Rakonjac, J. (2010). Identification of the gate regions in the primary structure of the secretin pIV. Mol Microbiol 76, 133-150.

Specthrie, L., Bullitt, E., Horiuchi, K., Model, P., Russel, M., and Makowski, L. (1992). Construction of a microphage variant of filamentous bacteriophage. J Mol Biol 228, 720 724.

Takeya, K., and Amako, K. (1966). A rod-shaped Pseudomonas phage. Virology 28, 163-165.

Thompson, J., Pope, T., Tung, J.S., Chan, C., Hollis, G., Mark, G., and Johnson, K.S. (1996). Affinity maturation of a high-affinity human monoclonal antibody against the third hypervariable loop of human immunodeficiency 
virus: use of phage display to improve affinity and broaden strain reactivity. J Mol Biol 256, 77-88.

Trenkner, E., Bonhoeffer, F., and Gierer, A. (1967). The fate of the protein component of bacteriophage fd during infection. Biochem Biophys Res Commun 28, 932-939.

Tseng, Y.H., Lo, M.C., Lin, K.C., Pan, C.C., and Chang, R.Y. (1990). Characterization of filamentous bacteriophage phi Lf from Xanthomonas campestris pv. campestris. J Gen Virol 71, 1881-1884.

Tsuboi, M., Tsunoda, M., Overman, S.A., Benevides, J.M., and Thomas, G.J., Jr. (2010). A structural model for the single-stranded DNA genome of filamentous bacteriophage Pf1. Biochemistry 49, 1737-1743.

Tsurushita, N., Fu, H., and Warren, C. (1996). Phage display vectors for in vivo recombination of immunoglobulin heavy and light chain genes to make large combinatorial libraries. Gene 172, 59-63.

Val, M.E., Bouvier, M., Campos, J., Sherratt, D., Cornet, F., Mazel, D., and Barre, F.X. (2005). The single-stranded genome of phage CTX is the form used for integration into the genome of Vibrio cholerae. Mol Cell 19, 559-566.

van Houten, N.E., Henry, K.A., Smith, G.P., and Scott, J.K. (2010). Engineering filamentous phage carriers to improve focusing of antibody responses against peptides. Vaccine 28, 2174-2185.

Velappan, N., Fisher, H.E., Pesavento, E., Chasteen, L., D'Angelo, S., Kiss, C., Longmire, M., Pavlik, P., and Bradbury, A.R. (2010). A comprehensive analysis of filamentous phage display vectors for cytoplasmic proteins: an analysis with different fluorescent proteins. Nucleic Acids Res 38, e22.

Vos, W.L., Nazarov, P.V., Koehorst, R.B., Spruijt, R.B., and Hemminga, M.A. (2009). From 'I' to 'L' and back again: the odyssey of membrane-bound M13 protein. Trends Biochem Sci 34, 249-255.

Waldor, M., and Mekalanos, J.J. (1996). Lysogenic conversion by a filamentous phage encoding cholera toxin. Science 272, 1910-1914.

Waldor, M.K., and Friedman, D.I. (2005). Phage regulatory circuits and virulence gene expression. Current opinion in microbiology 8, 459-465.

Waldor, M.K., Rubin, E.J., Pearson, G.D., Kimsey, H., and Mekalanos, J.J. (1997). Regulation, replication, and integration functions of the Vibrio cholerae CTX $\phi$ are encoded by region RS2. Mol Microbiol 24, 917-926.

Wall, T., Roos, S., Jacobsson, K., Rosander, A., and Jonsson, H. (2003). Phage display reveals 52 novel extracellular and transmembrane proteins from Lactobacillus reuteri DSM 20016(T). Microbiology 149, 3493-3505.

Wang, L., Zheng, A., Yi, L., Xu, C., Ding, M., and Deng, H. (2004). Identification of potential nuclear reprogramming and differentiation factors by a novel selection method for cloning chromatin-binding proteins. Biochem Biophys Res Commun 325, 302-307.

Waterhouse, P., Griffiths, A.D., Johnson, K.S., and Winter, G. (1993). Combinatorial infection and in vivo recombination: a strategy for making large phage antibody repertoires. Nucleic Acids Res 21, 2265-2266.
Webb, J.S., Lau, M., and Kjelleberg, S. (2004). Bacteriophage and phenotypic variation in Pseudomonas aeruginosa biofilm development. J Bacteriol 186, 8066-8073.

Weiss, G.A., Roth, T.A., Baldi, P.F., and Sidhu, S.S. (2003). Comprehensive mutagenesis of the C-terminal domain of the M13 gene-3 minor coat protein: the requirements for assembly into the bacteriophage particle. J Mol Biol 332, 777-782.

Wickner, W. (1975). Asymmetric orientation of a phage coat protein in cytoplasmic membrane of Escherichia coli. Proc Natl Acad Sci U S A 72, 4749-4753.

Willats, W.G., Gilmartin, P.M., Mikkelsen, J.D., and Knox, J.P. (1999). Cell wall antibodies without immunization: generation and use of de-esterified homogalacturonan block-specific antibodies from a naive phage display library. Plant J 18, 57-65.

Williams, D.D., Benedek, O., and Turnbough, C.L., Jr. (2003). Species-specific peptide ligands for the detection of Bacillus anthracis spores. Appl Environ Microbiol 69, 6288-6293.

Wiseman, R.L., and Day, L.A. (1977). Different packaging of DNA in the filamentous viruses Pf1 and Xf. J Mol Biol 116, 607-611.

Wrighton, N.C., Farrell, F.X., Chang, R., Kashyap, A.K., Barbone, F.P., Mulcahy, L.S., Johnson, D.L., Barrett, R.W., Jolliffe, L.K., and Dower, W.J. (1996). Small peptides as potent mimetics of the protein hormone erythropoietin. Science 273, 458-464.

Yang, Y.C., Chou, C.P., Kuo, T.T., Lin, S.H., and Yang, M.K. (2004). PilR enhances the sensitivity of Xanthomonas axonopodis $\mathrm{pv}$. citri to the infection of filamentous bacteriophage Cf. Curr Microbiol 48, 251-261.

Zacchi, P., Sblattero, D., Florian, F., Marzari, R., and Bradbury, A.R.M. (2003). Selecting open reading frames from DNA. Genome Research 13, 980-990.

Zenkin, N., Naryshkina, T., Kuznedelov, K., and Severinov, K. (2006). The mechanism of DNA replication primer synthesis by RNA polymerase. Nature 439, 617-620.

Zhang, L., Jacobsson, K., Strom, K., Lindberg, M., and Frykberg, L. (1999). Staphylococcus aureus expresses a cell surface protein that binds both $\operatorname{lgG}$ and beta2glycoprotein I. Microbiology 145, 177-183.

Zhang, Y. (2008). I-TASSER server for protein 3D structure prediction. BMC Bioinformatics 9, 40.

Zhou, B., Wirsching, P., and Janda, K.D. (2002). Human antibodies against spores of the genus Bacillus: a model study for detection of and protection against anthrax and the bioterrorist threat. Proc Natl Acad Sci U S A 99, 52415246.

Zinder, N.D., and Horiuchi, K. (1985). Multiregulatory elements of filamentous bacteriophages. Microbiol Rev 49, 101-106.

Zwick, M.B., Shen, J., and Scott, J.K. (2000). Homodimeric peptides displayed by the major coat protein of filamentous phage. J Mol Biol 300, 307-320. 


\section{Further Reading}

Caister Academic Press is a leading academic publisher of advanced texts in microbiology, molecular biology and medical research. Full details of all our publications at caister.com

- MALDI-TOF Mass Spectrometry in Microbiology Edited by: M Kostrzewa, S Schubert (2016) www.caister.com/malditof

- Aspergillus and Penicillium in the Post-genomic Era Edited by: RP Vries, IB Gelber, MR Andersen (2016) www.caister.com/aspergillus2

- The Bacteriocins: Current Knowledge and Future Prospects Edited by: RL Dorit, SM Roy, MA Riley (2016)

www.caister.com/bacteriocins

- Omics in Plant Disease Resistance Edited by: V Bhadauria (2016) www.caister.com/opd

- Acidophiles: Life in Extremely Acidic Environments Edited by: R Quatrini, DB Johnson (2016) www.caister.com/acidophiles

- Climate Change and Microbial Ecology: Current Research and Future Trend

Edited by: J Marxsen (2016)

www.caister.com/climate

- Biofilms in Bioremediation: Current Research and Emerging Technologies

Edited by: G Lear (2016)

www.caister.com/biorem

- Microalgae: Current Research and Applications Edited by: MN Tsaloglou (2016) www.caister.com/microalgae

- Gas Plasma Sterilization in Microbiology: Theory, Applications, Pitfalls and New Perspectives Edited by: H Shintani, A Sakudo (2016) www.caister.com/gasplasma

- Virus Evolution: Current Research and Future Directions Edited by: SC Weaver, M Denison, M Roossinck, et al. (2016) www.caister.com/virusevol

- Arboviruses: Molecular Biology, Evolution and Control Edited by: N Vasilakis, DJ Gubler (2016) www.caister.com/arbo

- Shigella: Molecular and Cellular Biology Edited by: WD Picking, WL Picking (2016) www.caister.com/shigella

-Aquatic Biofilms: Ecology, Water Quality and Wastewater Treatment

Edited by: AM Romaní, H Guasch, MD Balaguer (2016)

www.caister.com/aquaticbiofilms

- Alphaviruses: Current Biology

Edited by: S Mahalingam, L Herrero, B Herring (2016)

www.caister.com/alpha

- Thermophilic Microorganisms

Edited by: F Li (2015)

www.caister.com/thermophile
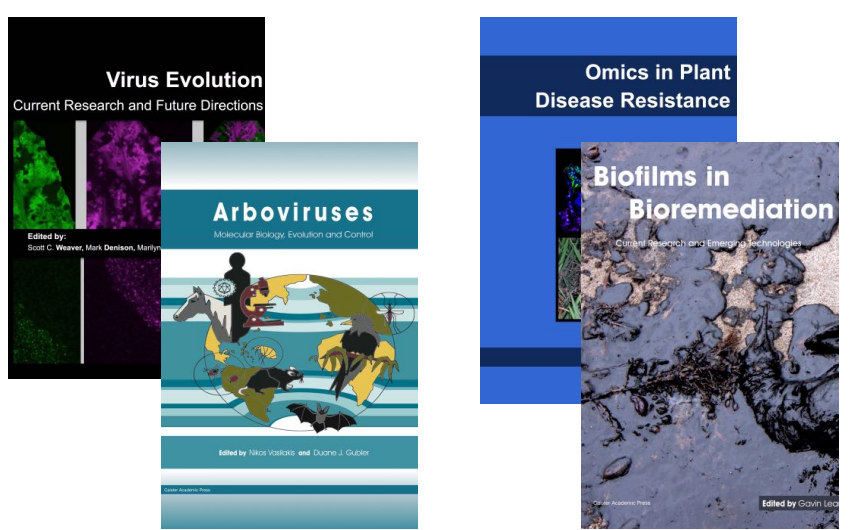
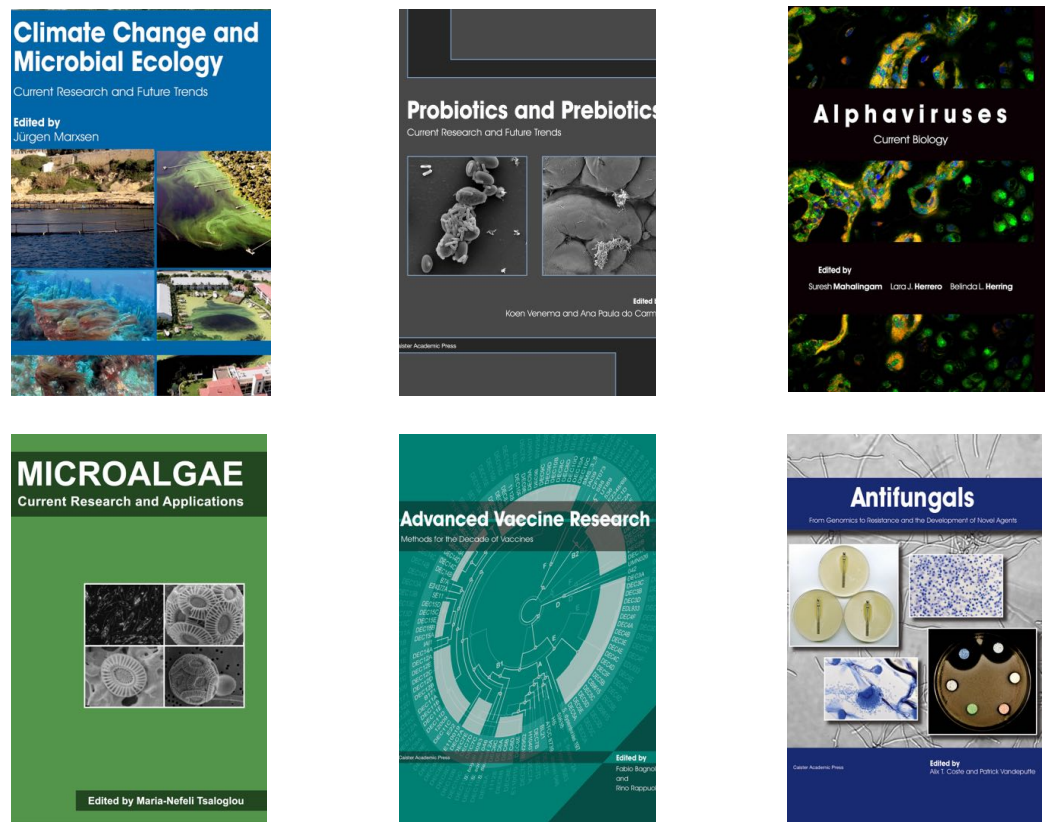

- Flow Cytometry in Microbiology: Technology and Applications Edited by: MG Wilkinson (2015) www.caister.com/flow

- Probiotics and Prebiotics: Current Research and Future Trends Edited by: K Venema, AP Carmo (2015) www.caister.com/probiotics

- Epigenetics: Current Research and Emerging Trends Edited by: BP Chadwick (2015) www.caister.com/epigenetics2015

- Corynebacterium glutamicum: From Systems Biology to Biotechnological Applications

Edited by: A Burkovski (2015)

www.caister.com/cory2

- Advanced Vaccine Research Methods for the Decade of Vaccines

Edited by: F Bagnoli, R Rappuoli (2015)

www.caister.com/vaccines

- Antifungals: From Genomics to Resistance and the Development of Novel Agents

Edited by: AT Coste, P Vandeputte (2015)

www.caister.com/antifungals

- Bacteria-Plant Interactions: Advanced Research and Future Trends Edited by: J Murillo, BA Vinatzer, RW Jackson, et al. (2015) www.caister.com/bacteria-plant

\section{- Aeromonas}

Edited by: J Graf (2015)

www.caister.com/aeromonas

- Antibiotics: Current Innovations and Future Trends

Edited by: S Sánchez, AL Demain (2015)

www.caister.com/antibiotics

- Leishmania: Current Biology and Contro Edited by: S Adak, R Datta (2015) www.caister.com/leish2

- Acanthamoeba: Biology and Pathogenesis (2nd edition) Author: NA Khan (2015)

www.caister.com/acanthamoeba2

- Microarrays: Current Technology, Innovations and Applications Edited by: Z He (2014)

www.caister.com/microarrays2

- Metagenomics of the Microbial Nitrogen Cycle: Theory, Methods and Applications

Edited by: D Marco (2014)

www.caister.com/n2 